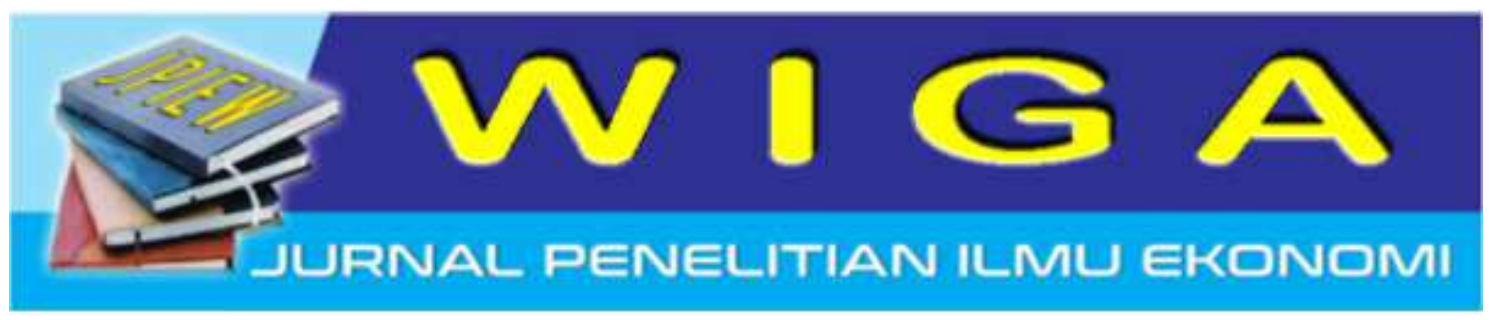

\title{
Pengujian Metode Fuzzy Time Series Chen dan Hsu Untuk Meramalkan Nilai Indeks Bursa Saham Syariah Di Jakarta Islamic Index (JII)
}

\author{
Rizka Zulfikar, Prihatini Ade`Mayvita \\ ${ }^{1,2)}$ Universitas Islam Kalimantan Muhammad Arsyad Al-Banjary Banjarmasin \\ 1) rizkazulfikar@gmail.com \\ 2) ademayvita@gmail.com
}

\begin{abstract}
This research is an empirical study to tested the accuracy of Chen and Hsu's Fuzzy Time Series Method used to forecast sharia market stock index in Jakarta Islamic Index. The data used in this research are secondary data consists of daily stock market indexes during 23 November 2016 to 14 July 2017. Chen dan Hsu's Fuzzied Series Method used in this research has the smallest MSE (Mean Square Error) and AFER (Average Forecasting Error Rate) value rather than others method such as Song and Chrissom (1993). Song and Chrissom (1994), Chen (1996), Hwang, Chen and Lee (1998), Huarng (2001) and Chen (2002). To tested the accuracy of the Chen's dan Hsu's Fuzzied Series Method researcher has to do 5 (five) steps such as (1) Determine lag between historical data, interval and The Universe Data (U), (2) Distributing Data into The Unniverse, (3) Define The Fuzzy Set, (4) Determine The Fuzzy Logical Relationship (FLR), and (5) Analyse the Difference between data. There are 3 (three) rules in Chen's dan Hsu's Fuzzied Series Method based on the Difference and FLR. The result of this research is Chen dan Hsu's Fuzzied Series Method has MSE $=1.88$ and AFER $=0.006 \%$ and it can be used to make forecasting on value and trend sharia stock market in Jakarta Islamic index.
\end{abstract}

Keywords :

Fuzzied Time Series, Chen and Hsu's method, Sharia Stocks Market,

\begin{abstract}
ABSTRAK
Penelitian ini merupakan sebuah studi empiris yang bertujuan menguji keakuratan metode Fuzzied Time Series Chen dan Hsu dalam meramalkan indeks bursa saham syariah di Jakarta Islamic Index. Data yang digunakan adalah data sekunder berupa data harian indeks bursa saham JII periode tanggal 23 Nopember 2016 sampai dengan 14 Juli 2017. Metode Fuzzied Time Series Chen dan Hsu digunakan dalam penelitian ini karena memberikan nilai MSE (Mean Square Error) dan AFER (Average Forecasting Error Rate) terkecil jika dibandingkan dengan metode lainnya seperti metode Song dan Chrissom (1993), Song dan dan Chrissom (1994), Chen (1996), Hwang, Chen dan Lee (1998), Huarng (2001) dan Chen (2002). Dalam melakukan pengujian terhadap metode Fuzzied Time Series Chen dan Hsu, peneliti harus melakukan 5 (lima) langkah penelitian seperti (1) menentukan selisih (lag) antar data, (2) Mendistribusikan data ke dalam Himpunan Semesta, (3) Mendefinisikan Fuzzy Set, (4) Menentukan Fuzzy Logical Relationship (FLR), dan (5) Menganalisa Difference antar data. Dalam metode ini ada 3 (tiga) aturan yang harus diikuti berdasarkan nilai Difference dan FLR. Hasil penelitian menunjukkan bahwa Fuzzied Time Series Chen dan Hsu memberikan nilai MSE =
\end{abstract}


Rizka Zulfikar; Prihatini, Pengujian Metode Fuzzy....

1.88 dan AFER $=0.006 \%$, sehingga metode ini dapat digunakan untuk meramalkan indeks dan trend bursa saham syariah di Jakarta Islamic Index.

Kata Kunci :

Fuzzied Time Series, Metode Chen dan Hsu, Indeks Bursa Saham Syariah, Peramalan.

\section{PENDAHULUAN}

Penelitian untuk mengkaji teknik peramalan harga saham telah banyak dilakukan namun masih sangat menarik untuk terus dikembangkan karena hingga saat ini belum ada teknik yang benar-benar dapat meramalkan secara tepat nilai harga saham yang akan datang.

Peramalan nilai harga saham sangat diperlukan oleh para investor untuk melakukan pengambilan keputusan, sehingga perlu adanya teknik-teknik permalan yang benar-benar dapat memberikan gambaran tentang pergerakan nilai harga saham yang merupakan data runtun waktu (time series).

Indeks bursa saham adalah indikator perdagangan saham, yang disusun dengan satu formula tertentu yang berlangsung di bursa efek. Di Indonesia kita mengenal beberapa indeks diantara seperti IHSG (Indeks Harga Saham Gabungan), JII (Jakarta Islamic Index), ISSI (Indonesa Saham Syariah Indonesia), LG45 (Indeks Saham LQ) dan sebagainya. Setiap bursa efek memiliki indeks harga saham yang berbeda-beda berdasarkan pergerakan harga saham yang termasuk di dalam bursa efek tersebut (Widoatmodjo, 2009).

Indeks bursa efek dapat menggambarkan kondisi pasar pada suatu saat, apakah pasar sedang aktif atau lesu. Dengan adanya indeks, kita dapat mengetahui tren pergerakan harga saham saat ini, apakah sedang naik, stabil atau turun. Pergerakan indeks menjadi indikator penting bagi para investor untuk menentukan apakah mereka akan menjual, menahan atau membeli suatu atau beberapa saham. Karena harga-harga saham bergerak dalam hitungan detik dan menit, maka nilai indeks pun bergerak turun naik dalam hitungan waktu yang cepat pula (Widoatmodjo, 2009)

Jakarta Islamic Index (JII) adalah indeks saham yang dibuat berdasarkan syariah Islam dan diluncurkan pada tanggal 3 Juli 2000. JII terdiri dari 30 saham yang dipilih dari saham - saham yang sesuai dengan syariah Islam dan dievaluasi setiap 6 bulan sekali dan saham-saham syariah yang termasuk dalam indeks JII merupakan saham yang terseleksi yang memiliki likuiditas dan kapitalisasi pasaryang tinggi sehingga bisa menggambarkan reaksi pasar modal syariah secara umum (Bursa Efek Indonesia, 2016).

Salah satu teknik yang saat ini banyak dikembangkan untuk melakukan peramalan adalah Teknik Fuzzied Time series yang digolongkan ke dalam konsep artificially intelegency atau konsep kecerdasan buatan yang dapat membantu untuk melakukan teknik peramalan. Teknik ini pertama kali diusulkan oleh Song dan Chissom (1993) yang menggunakan konsep logika fuzzy untuk mengembangkan dasar dari fuzzy time series dengan menggunakan metode time invariant dan time variant yang digunakan untuk melakukan peramalan. Ada beberapa metode fuzzy time series yang telah dikembangkan antara lain adalah metode Chen (1996 dan 2002) dan Chen dan Hsu (2004), metode weighted ( $\mathrm{Yu}, 2005)$, metode Markov (Sullivan dan Woodall, 1994), metode persentase perubahan (Stevenson dan Porter, 2009), penerapan jaringan back propagation (Huang dan $\mathrm{Yu}, 2006$ ), dan multiple-atribut metode fuzzy time series (Cheng et all, 2008).

Sistem peramalan dengan fuzzy time series telah banyak diuji oleh beberapa penelitian seperti yang dilakukan oleh Hansun (2012) dan Fauziah et all (2016) dengan metode Fuzzy Time Series Chen, 
Rizka Zulfikar; Prihatini, Pengujian Metode Fuzzy....

Rahmadiani (2012) dengan metode Fuzzy Neural Network, Handayani dan Anggraini (2015) dengan metode Chen dan metode Lee, Rukhansyah Et all (2015) dengan metode Fuzzy Time Series Markov Chain, dan Hasudungan (2016) dengan metode Fuzzy Time Series-Genetic Algorithm dan Elfajar (2017) dengan metode time invariant Fuzzy Time Series dimana hasil penelitian memberikan prediksi yang cukup baik dengan nilai Mean Square Error (MSE) dan error Average Forecasting Error Rate (AFER) yang kecil. Semakin kecil nilai error yang dihasilkan, maka dapat dikatakan bahwa hasil peramalan akan semakin baik (Rahmadiani, 2012).

Berdasarkan latar belakang di atas, maka tujuan dari penelitian adalah untuk menguji tingkat keakuratan metode Fuzzy Time Series yang dikemukakan oleh Chen dan Shu (2004) dalam meramalkan indeks bursa saham syariah di Jakarta Islamic Index.

\section{METODE PENELITIAN}

Penelitian ini merupakan studi empiris untuk menguji keakuratan suatu metode fuzzied time series dalam meramalkan pergerakan nilai indeks bursa saham di Jakarta Islamic Index (JII).

Populasi dan sampel dalam penelitian ini adalah data harian indeks bursa saham JII untuk tanggal periode 23 Nopember 2016 sampai dengan 14 Juli 2017 dengan jumlah data sebanyak 150 data indeks bursa saham. Jenis data yang digunakan dalam penelitian ini merupakan data sekunder yang diperoleh dari situs finance google (www.finance.google.com) untuk nilai indeks bursa saham JII. Adapun data indeks bursa saham JII selama periode pengamatan yang digunakan adalah sebagai berikut :

Tabel 1. Data Aktual Indeks Bursa Saham Jakarta Islamic Index Periode 23 Nopember 2016 - 14 Juli 2017.

\begin{tabular}{|c|c|c|}
\hline No & Tanggal & Indeks \\
\hline 1 & 23-Nov-16 & 689.93 \\
\hline 2 & 24-Nov-16 & 674.4 \\
\hline 3 & 25-Nov-16 & 677.97 \\
\hline 4 & 28-Nov-16 & 680.87 \\
\hline 5 & 29-Nov-16 & 685.62 \\
\hline 6 & $30-N o v-16$ & 682.71 \\
\hline 7 & 1-Dec-16 & 695.97 \\
\hline 8 & 2-Dec-16 & 703.4 \\
\hline 9 & 5-Dec-16 & 708.42 \\
\hline 10 & 6-Dec-16 & 705.69 \\
\hline 11 & 7-Dec-16 & 700.74 \\
\hline 12 & 8-Dec-16 & 706.43 \\
\hline 13 & 9-Dec-16 & 707.6 \\
\hline 14 & 13-Dec-16 & 705.69 \\
\hline 15 & 14-Dec-16 & 697.35 \\
\hline 16 & 15-Dec-16 & 694.24 \\
\hline 17 & 16-Dec-16 & 685.8 \\
\hline 18 & 19-Dec-16 & 679.4 \\
\hline No & Tanggal & Indeks \\
\hline 19 & 20-Dec-16 & 670.01 \\
\hline 20 & 21-Dec-16 & 666.57 \\
\hline 21 & 22-Dec-16 & 655.7 \\
\hline 22 & 23-Dec-16 & 648.1 \\
\hline 67 & 1-Mar-17 & 694.04 \\
\hline 68 & 2-Mar-17 & 698.02 \\
\hline 69 & 3-Mar-17 & 696.57 \\
\hline 70 & 6-Mar-17 & 705.44 \\
\hline
\end{tabular}

\begin{tabular}{|c|c|c|}
\hline No & Tanggal & Indeks \\
\hline 23 & 27-Dec-16 & 660.96 \\
\hline 24 & 28-Dec-16 & 680.22 \\
\hline 25 & 29-Dec-16 & 696.13 \\
\hline 26 & 30-Dec-16 & 694.13 \\
\hline 27 & 3-Jan-17 & 691.52 \\
\hline 28 & 4-Jan-17 & 696.36 \\
\hline 29 & 5-Jan-17 & 700.44 \\
\hline 30 & 6-Jan-17 & 703.87 \\
\hline 31 & 9-Jan-17 & 700.61 \\
\hline 32 & 10-Jan-17 & 701.11 \\
\hline 33 & 11-Jan-17 & 696.37 \\
\hline 34 & 12-Jan-17 & 692.49 \\
\hline 35 & 13-Jan-17 & 691.26 \\
\hline 36 & 16-Jan-17 & 688.18 \\
\hline 37 & 17-Jan-17 & 688.90 \\
\hline 38 & 18-Jan-17 & 696.12 \\
\hline 39 & 19-Jan-17 & 697.33 \\
\hline 40 & 20-Jan-17 & 687.24 \\
\hline No & Tanggal & Indeks \\
\hline 41 & 23-Jan-17 & 687.73 \\
\hline 42 & 24-Jan-17 & 694.63 \\
\hline 43 & 25-Jan-17 & 695.89 \\
\hline 44 & 26-Jan-17 & 699.37 \\
\hline 101 & 21-Apr-17 & 739.8 \\
\hline 102 & 25-Apr-17 & 740.17 \\
\hline 103 & 26-Apr-17 & 744.76 \\
\hline 104 & 27-Apr-17 & 744.21 \\
\hline
\end{tabular}

\begin{tabular}{|c|c|c|}
\hline No & Tanggal & Indeks \\
\hline 45 & 27-Jan-17 & 696.44 \\
\hline 46 & 30-Jan-17 & 690.59 \\
\hline 47 & 31-Jan-17 & 689.32 \\
\hline 48 & 1-Feb-17 & 696.28 \\
\hline 49 & 2-Feb-17 & 701.10 \\
\hline 50 & 3-Feb-17 & 702.44 \\
\hline 51 & 6-Feb-17 & 705.04 \\
\hline 52 & 7-Feb-17 & 700.30 \\
\hline 53 & 8-Feb-17 & 698.84 \\
\hline 54 & 9-Feb-17 & 698.60 \\
\hline 55 & 10-Feb-17 & 701.58 \\
\hline 56 & 13-Feb-17 & 705.13 \\
\hline 57 & 14-Feb-17 & 698.58 \\
\hline 58 & 16-Feb-17 & 701.57 \\
\hline 59 & 17-Feb-17 & 695.54 \\
\hline 60 & 20-Feb-17 & 694.66 \\
\hline 61 & 21-Feb-17 & 696.57 \\
\hline 62 & $22-F e b-17$ & 697.56 \\
\hline No & Tanggal & Indeks \\
\hline 63 & 23-Feb-17 & 698.01 \\
\hline 64 & 24-Feb-17 & 699.87 \\
\hline 65 & 27-Feb-17 & 698.02 \\
\hline 66 & 28-Feb-17 & 698.08 \\
\hline 135 & 15-Jun-17 & 744.04 \\
\hline 136 & 16-Jun-17 & 733.67 \\
\hline 137 & 19-Jun-17 & 734.02 \\
\hline 138 & 20-Jun-17 & 744.63 \\
\hline
\end{tabular}


Rizka Zulfikar; Prihatini, Pengujian Metode Fuzzy....

\begin{tabular}{|c|c|c|}
\hline 71 & 7-Mar-17 & 704.36 \\
\hline 72 & 8-Mar-17 & 698.66 \\
\hline 73 & 9-Mar-17 & 699.25 \\
\hline 74 & 10-Mar-17 & 695 \\
\hline 75 & 13-Mar-17 & 697.27 \\
\hline 76 & 14-Mar-17 & 700.22 \\
\hline 77 & 15-Mar-17 & 698.32 \\
\hline 78 & 16-Mar-17 & 717.57 \\
\hline 79 & 17-Mar-17 & 718.88 \\
\hline 80 & 20-Mar-17 & 717.3 \\
\hline 81 & 21-Mar-17 & 717.68 \\
\hline 82 & 22-Mar-17 & 714.85 \\
\hline 83 & 23-Mar-17 & 715.36 \\
\hline 84 & 24-Mar-17 & 716.14 \\
\hline 85 & 27-Mar-17 & 712.58 \\
\hline 86 & 29-Mar-17 & 724.27 \\
\hline 87 & 30-Mar-17 & 722.5 \\
\hline 88 & 31-Mar-17 & 718.35 \\
\hline 89 & 3-Apr-17 & 726.59 \\
\hline 90 & 4-Apr-17 & 735.07 \\
\hline 91 & 5-Apr-17 & 734.74 \\
\hline 92 & 6-Apr-17 & 729.4 \\
\hline 93 & 7-Apr-17 & 723.82 \\
\hline 94 & 10-Apr-17 & 721.06 \\
\hline 95 & 11-Apr-17 & 720.43 \\
\hline 96 & 12-Apr-17 & 726.57 \\
\hline 97 & 13-Apr-17 & 721.7 \\
\hline 98 & 17-Apr-17 & 713.85 \\
\hline 99 & 18-Apr-17 & 717.36 \\
\hline 100 & $20-A p r-17$ & 718.42 \\
\hline
\end{tabular}

\begin{tabular}{|r|r|r|}
\hline 105 & 28-Apr-17 & 738.19 \\
\hline 106 & 2-May-17 & 736.19 \\
\hline 107 & 3-May-17 & 727.66 \\
\hline 108 & 4-May-17 & 727.98 \\
\hline 109 & 5-May-17 & 726.82 \\
\hline 110 & 8-May-17 & 731.83 \\
\hline 111 & 9-May-17 & 728.33 \\
\hline 112 & 10-May-17 & 723.02 \\
\hline 113 & 12-May-17 & 726.12 \\
\hline 114 & 15-May-17 & 729.36 \\
\hline 115 & 16-May-17 & 726.61 \\
\hline 116 & 17-May-17 & 719.06 \\
\hline 117 & 18-May-17 & 720.16 \\
\hline 118 & 19-May-17 & 742.56 \\
\hline 119 & 22-May-17 & 738.15 \\
\hline 120 & 23-May-17 & 738.36 \\
\hline 121 & 24-May-17 & 733.25 \\
\hline 122 & 26-May-17 & 737.5 \\
\hline 123 & 29-May-17 & 734.95 \\
\hline 124 & 30-May-17 & 727.7 \\
\hline 125 & 31-May-17 & 733.69 \\
\hline 126 & 2-Jun-17 & 737.01 \\
\hline 127 & 5-Jun-17 & 738.12 \\
\hline 128 & 6-Jun-17 & 733.05 \\
\hline 129 & 7-Jun-17 & 735.43 \\
\hline 130 & 8-Jun-17 & 731.14 \\
\hline 131 & 9-Jun-17 & 727.89 \\
\hline 132 & 12-Jun-17 & 729.05 \\
\hline 133 & 13-Jun-17 & 734.8 \\
\hline 134 & 14-Jun-17 & 748.27 \\
\hline & & \\
\hline
\end{tabular}

\begin{tabular}{|r|r|r|}
\hline 139 & 21-Jun-17 & 748.59 \\
\hline 140 & 22-Jun-17 & 749.6 \\
\hline 141 & 3-Jul-17 & 764.64 \\
\hline 142 & 4-Jul-17 & 754.87 \\
\hline 143 & 5-Jul-17 & 751.06 \\
\hline 144 & 6-Jul-17 & 755.24 \\
\hline 145 & 7-Jul-17 & 749.02 \\
\hline 146 & 10-Jul-17 & 740.79 \\
\hline 147 & 11-Jul-17 & 743.32 \\
\hline 148 & 12-Jul-17 & 747.72 \\
\hline 149 & 13-Jul-17 & 748.01 \\
\hline 150 & 14-Jul-17 & 750.05 \\
\hline
\end{tabular}

Sumber : Google Finance

Metode yang digunakan adalah metode Fuzzied Time Series yang diusukan oleh Chen dan Hsu (2004) karena metode mereka memberikan nilai MSE dan AFER yang lebih baik dalam melakukan peramalan dibandingkan dengan metode lainnya seperti metode Song dan Chrissom
(1993). Song dan Chrissom (1994), Chen (1996), Hwang, Chen dan Lee (1998), Huarng (2001) dan Chen (2002).

Perbandingan nilai MSE dan AFER untuk beberapa metode fuzzied time series dapat dilihat pada tabel berikut ini :

Tabel 2. Perbandingan Nilai MSE dan AFER Metode Fuzzied Time Series.

\begin{tabular}{|c|l|c|c|}
\hline No & \multicolumn{1}{|c|}{ Metode } & MSE & AFER \\
\hline 1 & Song dan Chrissom (1993) & 423027 & $-0.617 \%$ \\
\hline 2 & Song dan Chrissom (1994) & 775687 & $0.962 \%$ \\
\hline No & \multicolumn{1}{|c|}{ Metode } & MSE & AFER \\
\hline 3 & Chen (1996) & 407507 & $-0.649 \%$ \\
\hline 4 & Huang, Chen dan Lee (1998) & 321418 & $-0.583 \%$ \\
\hline 5 & Huarng (2001) & 226611 & $-0.323 \%$ \\
\hline 6 & Chen (2002) & 86694 & $0.386 \%$ \\
\hline 7 & Chen dan Shu (2004) & 5353 & $0.089 \%$ \\
\hline
\end{tabular}

Sumber : Chen dan Shu (2004)

Metode Chen dan Hsu dilakukan dengan beberapa langkah sebagai berikut :
- Menentukan selisih (lag) antara data $\mathrm{n}+1$ dan data $\mathrm{n}$ dengan rumus :

$$
\text { Selisih }(\text { Lag })=\text { Data }_{n+1}-\text { Data }_{n}
$$

(1)

\section{Langkah 1 :}


- Menjumlahkan seluruh selisih yang didapat dan selanjutnya dibagi dengan banyaknya jumlah data.

Total Selisih $=\sum($ Data $n+1-$ Data $n)$

Selanjutnya total selisih dibagi dengan banyaknya data.

- Menentukan panjang interval dengan cara Total selisih yang telah dibagi dengan banyaknya data selanjutnya dibagi 2.

Panjang Interval $=($ Total selisih $/$ Banyak

$$
\text { Data)/2 (3) }
$$

- Menentukan banyaknya kelas adalah dengan cara selisih data terbesar dengan data terkecil dibagi dengan panjang interval.

Banyaknya Kelas $=\frac{\text { D Max }-D \text { Min }}{\text { Panjang Interval }}$

- Masing-masing kelas disimbolkan dengan himpunan semesta (Universe) $=\mathrm{U} 1, \mathrm{U} 2, \mathrm{U} 3 \mathrm{~s} / \mathrm{d} \mathrm{U} 23$. sesuai dengan banyaknya kelas.

- Definisikan himpunan semesta masing-masing kelas sesuai dengan panjang interval masing-masing kelas.

\section{Langkah 2 :}

- Mendistribusikan seluruh data penelitian ke dalam masing-masing himpunan semesta.

- Menentukan banyaknya data yang termasuk ke dalam masing-masing kelas interval.

- Melakukan redivided Interval dengan ketentuan untuk kelas interval dengan jumlah data terbanyak selanjutnya interval dibagi 4 sama besar, kelas interval terbanyak kedua dibagi 3 sama besar, kelas interval terbanyak ketiga dibagi 2 sama besar. Untuk kelas interval yang tidak memiliki anggota data bisa dihilangkan.

\section{Langkah 3 :}

- Mendefinisikan fuzzy set, dengan cara mengasumsikan variabel linguistik dari selisih yang akan digunakan untuk nilai linguistik himpunan fuzzy berdasarkan interval yang dibentuk pada langkah 3 dan fuzzy set akan mewakili data aktual indeks saham JII dengan $1 \leq \mathrm{i} \leq 34$.

- Selanjutnya masing-masing interval dari fuzzy set dibagi 4 bagian sama panjang, dimana 0.25 bagian dan 0.75 bagian dari interval digunakan sebagai downward dan upward.

\section{Langkah 4 :}

- Mendistribusikan fuzzy set yang telah dibentuk ke dalam tabel data aktual.

- Membentuk Fuzzy Logical Relationship (FLR) berdasarkan tabel data fuzzy set pada langkah 5 dimana FLR dalam bentuk " $A_{i} \rightarrow A_{j}$ " yang berarti "Jika hasil fuzzifikasi data $n-1$ adalah $\mathrm{A}_{i}$ maka fuzzifikasi data ke $\mathrm{n}$ adalah $\mathrm{A}_{\mathrm{j}}$ " (Chen dan Hsu, 2004).

\section{Langkah 5 :}

- Menentukan Difference antara data n-1 degan n-2 (Diff 1-2) dan Difference antara data n-2 dengan n-3 (Diff 2-3).

- Menentukan selisih antara (Diff 1-2) (Diff 2-3) yang kemudian dilambangkan dengan DIFF.

- Menentukan nilai DIFF x 2 + Data n-1 dan nilai DIFF / 2 + Data $n-1$.

Dalam pengujian akurasi peramalan dengan metode Fuzzied Time Series Chen dan Hsu (2004) ada beberapa aturan yang harus diikuti dalam menentukan nilai ramalan, yaitu :

\section{Aturan 1 :}

- Apabila data yang dianalisa tidak memiliki data n-2 dan n-3, maka yang digunakan apabila adalah middle value dari Fuzzie Set $A_{j}$.

- Apabila data yang dianalisa tidak memiliki data n-3, maka :

a) apabila selisih n-1 dan n-2 > setengah interval $A_{j}$ maka nilai 
Rizka Zulfikar; Prihatini, Pengujian Metode Fuzzy....

ramalan dinyatakan sebagai upward 0.75 point interval $A_{j}$.

b) apabila selisih $\mathrm{n}-1$ dan $\mathrm{n}-2=$ setengah interval $A_{j}$ maka nilai ramalan dinyatakan sebagai Middle Value interval $A_{j}$

c) apabila selisih n-1 dan n-2 < setengah interval $A_{j}$ maka nilai ramalan dinyatakan sebagai Downward interval $\mathrm{A}_{\mathrm{j}}$.

\section{Aturan 2 :}

- Jika DIFF bernilai postif maka :

a) apabila nilai (DIFF x 2 + Data n-1) ada di dalam interval $A_{j}$ maka nilai ramalan dinyatakan sebagai upward 0.75 point interval $A_{j}$.

b) apabila nilai (DIFF / 2 + Data n-1) ada di dalam interval $A_{j}$ maka nilai ramalan dinyatakan sebagai downward 0.25 point interval $\mathrm{A}_{\mathrm{j}}$.

c) Point (a) dan point (b) tidak terpenuhi maka nilai ramalan dinyatakan dengan nilai Middle Value interval $\mathrm{A}_{\mathrm{j}}$.

Aturan 3 :

- Jika DIFF bernilai negatif maka :

a) apabila nilai (DIFF / 2 + Data n-1) ada di dalam interval $A_{j}$ maka nilai ramalan dinyatakan sebagai downward 0.25 point interval $\mathrm{A}_{\mathrm{j}}$.

\section{HASIL DAN PEMBAHASAN}

Setelah dilakukan analisa terhadap data aktual maka hasil yang didapatkan dari langkah-langkah Fuzzied Time Series Metode Chen dan Hsu adalah sebagai berikut :

- $\quad$ Total selisih data aktual $=1449,99$ dengan banyaknya data $=150$, maka b) apabila nilai (DIFF x 2 + Data n-1) ada di dalam interval $A_{j}$ maka nilai ramalan dinyatakan sebagai upward 0.75 point interval $A_{j}$.

c) Jika Point (a) dan point (b) tidak terpenuhi maka nilai ramalan dinyatakan dengan nilai Middle Value interval $A_{j}$.

\section{Mean Square Error (MSE)}

MSE digunakan untuk membandingkan tingkat akurasi berbagai metode peramalan (Chen dan Hsu, 2004), dimana rumus untuk menghitung MSE adalah sebagai berikut :

MSE $=$

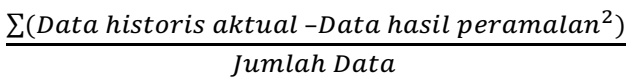

(5)

\section{Average Forecasting Error Rate (AFER)}

AFER digunakan untuk mengetahui besarnya kesalahan yang terjadi pada data hasil peramalan terhadap data aktual (Jilani, Burney dan Ardil, 2007) yang dihitung berdasarkan persamaan berikut ini :

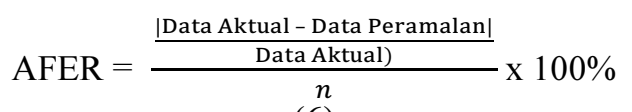

(6)

panjang interval didapatkan $=4,83$ yang kemudian dibulatkan menjadi 5 .

- $\quad$ Pada data penelitian data $\max =764,4$ dan data $\min =648,1$, maka :

Banyaknya Kelas $=\frac{764,4-648,1}{4,83}=$

24,1 atau dibulatkan menjadi 24 kelas.

- Himpunan semesta (U) $=[648.1$, 764.4]

- Hasil pendefinisian masing-masing himpunan semesta sesuai dengan kelas interval adalah sebagai berikut : 
Rizka Zulfikar; Prihatini, Pengujian Metode Fuzzy....

$\begin{array}{lll}-\mathrm{U} 1 & =[645-650] & -\mathrm{U} 13=[705-710] \\ -\mathrm{U} 2 & =[650-655] & -\mathrm{U} 14=[710-715] \\ -\mathrm{U} 3 & =[655-660] & -\mathrm{U} 15=[715-720] \\ -\mathrm{U} 4=[660-665] & -\mathrm{U} 16=[720-725] \\ -\mathrm{U} 5=[665-670] & -\mathrm{U} 17=[725-730] \\ -\mathrm{U} 6=[670-675] & -\mathrm{U} 18=[730-735] \\ -\mathrm{U} 7=[675-680] & -\mathrm{U} 19=[735-740] \\ -\mathrm{U} 8=[680-685] & -\mathrm{U} 20=[740-745] \\ -\mathrm{U} 9=[685-690] & -\mathrm{U} 21=[745-750] \\ -\mathrm{U} 10=[690-695] & -\mathrm{U} 22=[750-755] \\ -\mathrm{U} 11=[695-700] & -\mathrm{U} 23=[755-760] \\ -\mathrm{U} 12=[700-705] & -\mathrm{U} 24=[760-765]\end{array}$

- Hasil distribusi data aktual ke dalam himpunan semesta sebanyak 24 kelas

- $\quad$ interval adalah sesuai tabel berikut :

Tabel 3. Hasil Distribusi Data Aktual Ke dalam Himpunan Semesta

\begin{tabular}{|r|r|c|r|r|c|}
\hline \multicolumn{1}{l|l}{ No } & \multicolumn{1}{l|}{ Indeks } & \multicolumn{1}{c|}{$\begin{array}{c}\text { Himpunan } \\
\text { Semesta }\end{array}$} & \multicolumn{1}{l|}{ No } & \multicolumn{1}{l|}{ Indeks } & \multicolumn{1}{c|}{$\begin{array}{c}\text { Himpunan } \\
\text { Semesta }\end{array}$} \\
\hline 1 & 689.93 & $\mathrm{U} 9$ & 76 & 700.22 & $\mathrm{U} 12$ \\
\hline 2 & 674.4 & $\mathrm{U} 6$ & 77 & 698.32 & $\mathrm{U} 11$ \\
\hline 3 & 677.97 & $\mathrm{U} 7$ & 78 & 717.57 & $\mathrm{U} 15$ \\
\hline 4 & 680.87 & $\mathrm{U} 8$ & 79 & 718.88 & $\mathrm{U} 15$ \\
\hline 5 & 685.62 & $\mathrm{U} 9$ & 80 & 717.30 & $\mathrm{U} 15$ \\
\hline$\ldots$ & $\ldots \ldots \ldots \ldots$ & $\ldots \ldots \ldots .$. & $\ldots \ldots$ & $\ldots \ldots \ldots .$. & $\ldots \ldots \ldots .$. \\
\hline$\ldots$ & $\ldots \ldots \ldots .$. & $\ldots \ldots \ldots$. & $\ldots \ldots$ & $\ldots \ldots \ldots$. & $\ldots \ldots \ldots$. \\
\hline 70 & 705.44 & $\mathrm{U} 13$ & 145 & 749.02 & $\mathrm{U} 21$ \\
\hline 71 & 704.36 & $\mathrm{U} 12$ & 146 & 740.79 & $\mathrm{U} 20$ \\
\hline 72 & 698.66 & $\mathrm{U} 11$ & 147 & 743.32 & $\mathrm{U} 20$ \\
\hline 73 & 699.25 & $\mathrm{U} 11$ & 148 & 747.72 & $\mathrm{U} 21$ \\
\hline 74 & 695.00 & $\mathrm{U} 10$ & 149 & 748.01 & $\mathrm{U} 21$ \\
\hline 75 & 697.27 & $\mathrm{U} 11$ & 150 & 750.05 & $\mathrm{U} 22$ \\
\hline
\end{tabular}

- Jumlah data berdasarkan kelas interval adalah sebagai berikut :

\begin{tabular}{|c|c|c|c|c|c|c|c|}
\hline - U1 & $=$ & 1 & Data & - U13 & $=$ & 8 & Data \\
\hline - $\quad$ U2 & $=$ & 0 & Data & - U14 & $=$ & 3 & Data \\
\hline U3 & $=$ & 1 & Data & - U15 & $=$ & 10 & Data \\
\hline - U4 & $=$ & 1 & Data & - U16 & $=$ & 8 & $\mathrm{Da}$ \\
\hline - U5 & $=$ & 1 & Data & - U17 & $=$ & 13 & 100 \\
\hline U6 & $=$ & 2 & Data & - U18 & $=$ & 10 & $\mathrm{Da}$ \\
\hline - $\quad$ U7 & $=$ & 2 & Data & - U19 & $=$ & 10 & Da \\
\hline - $\quad$ U8 & $=$ & 3 & Data & - U20 & $=$ & 8 & Da \\
\hline - U9 & $=$ & 8 & Data & - U21 & $=$ & 6 & Da \\
\hline - U10 & $=$ & 10 & Data & - U22 & $=$ & 3 & $\mathrm{Da}$ \\
\hline - U11 & $=$ & 27 & Data & - U23 & $=$ & 1 & $\mathrm{Da}$ \\
\hline U12 & $=$ & 13 & Data & - U24 & $=$ & 1 & \\
\hline
\end{tabular}


Rizka Zulfikar; Prihatini, Pengujian Metode Fuzzy....

- Hasil redivided interval :

Tabel 4. Redivided Interval

\begin{tabular}{|c|c|c|c|c|c|}
\hline \multicolumn{3}{|c|}{ Himpunan Semesta } & Keterangan & Action & Sub Interval \\
\hline U11 & $=27$ & Data & Terbanyak Pertama & Interval Dibagi 4 & $\begin{array}{l}\text { U11.1 } \\
\text { U11.2 } \\
\text { U11.3 } \\
\text { U11.4 }\end{array}$ \\
\hline U12 & $=13$ & Data & Terbanyak kedua & Interval Dibagi 3 & $\begin{array}{l}\text { U12.1 } \\
\text { U12.2 } \\
\text { U12.3 }\end{array}$ \\
\hline U17 & $=13$ & Data & Terbanyak Kedua & Interval Dibagi 3 & $\begin{array}{l}\text { U17.1 } \\
\text { U17.2 } \\
\text { U17.3 }\end{array}$ \\
\hline U10 & $=10$ & Data & Terbanyak Ketiga & Interval Dibagi 2 & $\begin{array}{l}\text { U10.1 } \\
\text { U10.2 }\end{array}$ \\
\hline U15 & $=10$ & Data & Terbanyak Ketiga & Interval Dibagi 2 & $\begin{array}{l}\text { U15.1 } \\
\text { U15.2 }\end{array}$ \\
\hline U18 & $=10$ & Data & Terbanyak Ketiga & Interval Dibagi 2 & $\begin{array}{l}\text { U18.1 } \\
\text { U18.2 }\end{array}$ \\
\hline U19 & $=10$ & Data & Terbanyak Ketiga & Interval Dibagi 2 & $\begin{array}{l}\text { U19.1 } \\
\text { U19.2 }\end{array}$ \\
\hline
\end{tabular}

- Setelah hal di atas dilakukan, maka kelas interval menjadi sebagai berikut :

\begin{tabular}{|c|c|c|c|c|c|}
\hline - U1 & $=$ & {$[645-650]$} & - U13 & $=$ & {$[705-710]$} \\
\hline - U3 & $=$ & {$[655-660]$} & - U14 & $=$ & {$\left[\begin{array}{lll}710 & -715]\end{array}\right.$} \\
\hline - U4 & $=$ & {$[660-665]$} & - U15.1 & $=$ & {$[715-717.5]$} \\
\hline - U5 & $=$ & {$[665-670]$} & - U15.2 & $=$ & {$[717.5-720]$} \\
\hline - U6 & $=$ & {$\left[\begin{array}{ll}670 & -675\end{array}\right]$} & - U16 & $=$ & {$[720-725]$} \\
\hline - U7 & $=$ & {$[675-680]$} & - U17.1 & $=$ & {$\left[\begin{array}{ll}725 & -726.67]\end{array}\right.$} \\
\hline - U8 & $=$ & {$[680-685]$} & - U17.2 & $=$ & {$[726.67-728.33]$} \\
\hline - U9 & $=$ & {$[685-690]$} & - U17.3 & $=$ & {$[728.33-730]$} \\
\hline - U10.1 & $=$ & {$[690-692.5]$} & - U18.1 & $=$ & {$[730-732.5]$} \\
\hline - U10.2 & $=$ & {$[692.5-695]$} & - U18.2 & $=$ & {$[732.5-735]$} \\
\hline - U11.1 & $=$ & {$\left[\begin{array}{ll}695 & -696.25]\end{array}\right.$} & - U19.1 & $=$ & {$[735-737.5]$} \\
\hline - U11.2 & $=$ & {$\left[\begin{array}{lll}696.25 & -697.5\end{array}\right]$} & - U19.2 & $=$ & {$[737.5-740]$} \\
\hline - U11.3 & $=$ & {$[697.5-698.75]$} & - U20 & $=$ & {$[740-745]$} \\
\hline - U11.4 & $=$ & 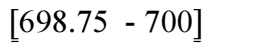 & - U21 & $=$ & {$[745-750]$} \\
\hline - U12.1 & $=$ & {$\left[\begin{array}{ll}700 & -701.67\end{array}\right]$} & - U22 & $=$ & {$[750-755]$} \\
\hline - U12.2 & $=$ & 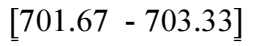 & - U23 & $=$ & {$[755-760]$} \\
\hline - U12.3 & $=$ & 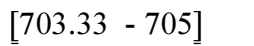 & - U24 & $=$ & {$\left[\begin{array}{ll}760 & -765\end{array}\right]$} \\
\hline
\end{tabular}

- Hasil Fuzzifikasi berupa nilai linguistik pada tiap himpunan fuzzy berdasarkan data aktual adalah sebagai berikut : $\begin{aligned} \mathrm{A}_{1}= & \mathbf{1} / \mathrm{U}_{1}+\mathbf{0 . 5} / \mathrm{U}_{\mathbf{2}}+0 / \mathrm{U}_{3}+0 / \mathrm{U}_{4}+0 / \mathrm{U}_{5}+0 / \mathrm{U}_{6}+0 / \mathrm{U}_{7}+0 / \mathrm{U}_{8}+0 / \mathrm{U}_{9}+0 / \mathrm{U}_{10.1}+0 / \mathrm{U}_{10.2}+0 / \mathrm{U}_{11.1}+ \\ & 0 / \mathrm{U}_{11.2}+0 / \mathrm{U}_{11.3}+0 / \mathrm{U}_{11.4}+0 / \mathrm{U}_{12.1}+0 / \mathrm{U}_{12.2}+0 / \mathrm{U}_{12.3}+0 / \mathrm{U}_{13}+0 / \mathrm{U}_{14}+0 / \mathrm{U}_{15.1}+0 / \mathrm{U}_{15.2}+0 / \mathrm{U}_{16} \\ & +0 / \mathrm{U}_{17.1}+0 / \mathrm{U}_{17.2}+0 / \mathrm{U}_{17.3}+0 / \mathrm{U}_{18.1}+0 / \mathrm{U}_{18.2}+0 / \mathrm{U}_{19.1}+0 / \mathrm{U}_{19.2}+0 / \mathrm{U}_{20}+0 / \mathrm{U}_{21}+0 / \mathrm{U}_{22}+ \\ & 0 / \mathrm{U}_{23}+0 / \mathrm{U}_{24} .\end{aligned}$ 
$\mathrm{A} 2=\mathbf{0 . 5} / \mathbf{U}_{\mathbf{1}}+\mathbf{1} / \mathbf{U}_{\mathbf{2}}+\mathbf{0 . 5} / \mathbf{U}_{\mathbf{3}}+0 / \mathrm{U}_{4}+0 / \mathrm{U}_{5}+0 / \mathrm{U}_{6}+0 / \mathrm{U}_{7}+0 / \mathrm{U}_{8}+0 / \mathrm{U}_{9}+0 / \mathrm{U}_{10.1}+0 / \mathrm{U}_{10.2}+0 / \mathrm{U}_{11.1}$ $+0 / \mathrm{U}_{11.2}+0 / \mathrm{U}_{11.3}+0 / \mathrm{U}_{11.4}+0 / \mathrm{U}_{12.1}+0 / \mathrm{U}_{12.2}+0 / \mathrm{U}_{12.3}+0 / \mathrm{U}_{13}+0 / \mathrm{U}_{14}+0 / \mathrm{U}_{15.1}+0 / \mathrm{U}_{15.2}+$ $0 / \mathrm{U}_{16}+0 / \mathrm{U}_{17.1}+0 / \mathrm{U}_{17.2}+0 / \mathrm{U}_{17.3}+0 / \mathrm{U}_{18.1}+0 / \mathrm{U}_{18.2}+0 / \mathrm{U}_{19.1}+0 / \mathrm{U}_{19.2}+0 / \mathrm{U}_{20}+0 / \mathrm{U}_{21}+0 / \mathrm{U}_{22}$ $+0 / \mathrm{U}_{23}+0 / \mathrm{U}_{24}$

$\mathrm{A} 3=0 / \mathrm{U}_{1}+\mathbf{0 . 5} / \mathbf{U}_{\mathbf{2}}+\mathbf{1} / \mathbf{U}_{\mathbf{3}}+\mathbf{0 . 5} / \mathbf{U}_{\mathbf{4}}+0 / \mathrm{U}_{5}+0 / \mathrm{U}_{6}+0 / \mathrm{U}_{7}+0 / \mathrm{U}_{8}+0 / \mathrm{U}_{9}+0 / \mathrm{U}_{10.1}+0 / \mathrm{U}_{10.2}+0 / \mathrm{U}_{11.1}$ $+0 / \mathrm{U}_{11.2}+0 / \mathrm{U}_{11.3}+0 / \mathrm{U}_{11.4}+0 / \mathrm{U}_{12.1}+0 / \mathrm{U}_{12.2}+0 / \mathrm{U}_{12.3}+0 / \mathrm{U}_{13}+0 / \mathrm{U}_{14}+0 / \mathrm{U}_{15.1}+0 / \mathrm{U}_{15.2}+$ $0 / \mathrm{U}_{16}+0 / \mathrm{U}_{17.1}+0 / \mathrm{U}_{17.2}+0 / \mathrm{U}_{17.3}+0 / \mathrm{U}_{18.1}+0 / \mathrm{U}_{18.2}+0 / \mathrm{U}_{19.1}+0 / \mathrm{U}_{19.2}+0 / \mathrm{U}_{20}+0 / \mathrm{U}_{21}+0 / \mathrm{U}_{22}$ $+0 / \mathrm{U}_{23}+0 / \mathrm{U}_{24}$.

$\mathrm{A} 4=0 / \mathrm{U}_{1}+0 / \mathrm{U}_{2}+\mathbf{0 . 5} / \mathbf{U}_{\mathbf{3}}+\mathbf{1} / \mathbf{U}_{\mathbf{4}}+\mathbf{0 . 5} / \mathbf{U}_{\mathbf{5}}+0 / \mathrm{U}_{6}+0 / \mathrm{U}_{7}+0 / \mathrm{U}_{8}+0 / \mathrm{U}_{9}+0 / \mathrm{U}_{10.1}+0 / \mathrm{U}_{10.2}+0 / \mathrm{U}_{11.1}$ $+0 / \mathrm{U}_{11.2}+0 / \mathrm{U}_{11.3}+0 / \mathrm{U}_{11.4}+0 / \mathrm{U}_{12.1}+0 / \mathrm{U}_{12.2}+0 / \mathrm{U}_{12.3}+0 / \mathrm{U}_{13}+0 / \mathrm{U}_{14}+0 / \mathrm{U}_{15.1}+0 / \mathrm{U}_{15.2}+$ $0 / \mathrm{U}_{16}+0 / \mathrm{U}_{17.1}+0 / \mathrm{U}_{17.2}+0 / \mathrm{U}_{17.3}+0 / \mathrm{U}_{18.1}+0 / \mathrm{U}_{18.2}+0 / \mathrm{U}_{19.1}+0 / \mathrm{U}_{19.2}+0 / \mathrm{U}_{20}+0 / \mathrm{U}_{21}+0 / \mathrm{U}_{22}$ $+0 / \mathrm{U}_{23}+0 / \mathrm{U}_{24}$

$\mathrm{A} 5=0 / \mathrm{U}_{1}+0 / \mathrm{U}_{2}+0 / \mathrm{U}_{3}+\mathbf{0 . 5} / \mathbf{U}_{\mathbf{4}}+\mathbf{1} / \mathbf{U}_{\mathbf{5}}+\mathbf{0 . 5} / \mathbf{U}_{\mathbf{6}}+0 / \mathrm{U}_{7}+0 / \mathrm{U}_{8}+0 / \mathrm{U}_{9}+0 / \mathrm{U}_{10.1}+0 / \mathrm{U}_{10.2}+0 / \mathrm{U}_{11.1}$ $+0 / \mathrm{U}_{11.2}+0 / \mathrm{U}_{11.3}+0 / \mathrm{U}_{11.4}+0 / \mathrm{U}_{12.1}+0 / \mathrm{U}_{12.2}+0 / \mathrm{U}_{12.3}+0 / \mathrm{U}_{13}+0 / \mathrm{U}_{14}+0 / \mathrm{U}_{15.1}+0 / \mathrm{U}_{15.2}+$ $0 / \mathrm{U}_{16}+0 / \mathrm{U}_{17.1}+0 / \mathrm{U}_{17.2}+0 / \mathrm{U}_{17.3}+0 / \mathrm{U}_{18.1}+0 / \mathrm{U}_{18.2}+0 / \mathrm{U}_{19.1}+0 / \mathrm{U}_{19.2}+0 / \mathrm{U}_{20}+0 / \mathrm{U}_{21}+0 / \mathrm{U}_{22}$ $+0 / \mathrm{U}_{23}+0 / \mathrm{U}_{24}$

A6 $=0 / \mathrm{U}_{1}+0 / \mathrm{U}_{2}+0 / \mathrm{U}_{3}+0 / \mathrm{U}_{4}+\mathbf{0 . 5} / \mathbf{U}_{\mathbf{5}}+1 / \mathbf{U}_{\mathbf{6}}+\mathbf{0 . 5} / \mathbf{U}_{7}+0 / \mathrm{U}_{8}+0 / \mathrm{U}_{9}+0 / \mathrm{U}_{10.1}+0 / \mathrm{U}_{10.2}+0 / \mathrm{U}_{11.1}$ $+0 / \mathrm{U}_{11.2}+0 / \mathrm{U}_{11.3}+0 / \mathrm{U}_{11.4}+0 / \mathrm{U}_{12.1}+0 / \mathrm{U}_{12.2}+0 / \mathrm{U}_{12.3}+0 / \mathrm{U}_{13}+0 / \mathrm{U}_{14}+0 / \mathrm{U}_{15.1}+0 / \mathrm{U}_{15.2}+$ $0 / \mathrm{U}_{16}+0 / \mathrm{U}_{17.1}+0 / \mathrm{U}_{17.2}+0 / \mathrm{U}_{17.3}+0 / \mathrm{U}_{18.1}+0 / \mathrm{U}_{18.2}+0 / \mathrm{U}_{19.1}+0 / \mathrm{U}_{19.2}+0 / \mathrm{U}_{20}+0 / \mathrm{U}_{21}+0 / \mathrm{U}_{22}$ $+0 / \mathrm{U}_{23}+0 / \mathrm{U}_{24}$

$\mathrm{A} 7=0 / \mathrm{U}_{1}+0 / \mathrm{U}_{2}+0 / \mathrm{U}_{3}+0 / \mathrm{U}_{4}+0 / \mathrm{U}_{5}+\mathbf{0 . 5} / \mathbf{U}_{\mathbf{6}}+\mathbf{1} / \mathbf{U}_{7}+\mathbf{0 . 5} / \mathbf{U}_{\mathbf{8}}+0 / \mathrm{U}_{9}+0 / \mathrm{U}_{10.1}+0 / \mathrm{U}_{10.2}+0 / \mathrm{U}_{11.1}$ $+0 / \mathrm{U}_{11.2}+0 / \mathrm{U}_{11.3}+0 / \mathrm{U}_{11.4}+0 / \mathrm{U}_{12.1}+0 / \mathrm{U}_{12.2}+0 / \mathrm{U}_{12.3}+0 / \mathrm{U}_{13}+0 / \mathrm{U}_{14}+0 / \mathrm{U}_{15.1}+0 / \mathrm{U}_{15.2}+$ $0 / \mathrm{U}_{16}+0 / \mathrm{U}_{17.1}+0 / \mathrm{U}_{17.2}+0 / \mathrm{U}_{17.3}+0 / \mathrm{U}_{18.1}+0 / \mathrm{U}_{18.2}+0 / \mathrm{U}_{19.1}+0 / \mathrm{U}_{19.2}+0 / \mathrm{U}_{20}+0 / \mathrm{U}_{21}+0 / \mathrm{U}_{22}$ $+0 / \mathrm{U}_{23}+0 / \mathrm{U}_{24}$

$\mathrm{A} 8=0 / \mathrm{U}_{1}+0 / \mathrm{U}_{2}+0 / \mathrm{U}_{3}+0 / \mathrm{U}_{4}+0 / \mathrm{U}_{5}+0 / \mathrm{U}_{6}+\mathbf{0 . 5} / \mathbf{U}_{7}+\mathbf{1} / \mathbf{U}_{\mathbf{8}}+\mathbf{0 . 5} / \mathbf{U}_{\mathbf{9}}+0 / \mathrm{U}_{10.1}+0 / \mathrm{U}_{10.2}+0 / \mathrm{U}_{11.1}$ $+0 / \mathrm{U}_{11.2}+0 / \mathrm{U}_{11.3}+0 / \mathrm{U}_{11.4}+0 / \mathrm{U}_{12.1}+0 / \mathrm{U}_{12.2}+0 / \mathrm{U}_{12.3}+0 / \mathrm{U}_{13}+0 / \mathrm{U}_{14}+0 / \mathrm{U}_{15.1}+0 / \mathrm{U}_{15.2}+$ $0 / \mathrm{U}_{16}+0 / \mathrm{U}_{17.1}+0 / \mathrm{U}_{17.2}+0 / \mathrm{U}_{17.3}+0 / \mathrm{U}_{18.1}+0 / \mathrm{U}_{18.2}+0 / \mathrm{U}_{19.1}+0 / \mathrm{U}_{19.2}+0 / \mathrm{U}_{20}+0 / \mathrm{U}_{21}+0 / \mathrm{U}_{22}$ $+0 / \mathrm{U}_{23}+0 / \mathrm{U}_{24}$.

A33 $=0 / \mathrm{U}_{1}+0 / \mathrm{U}_{2}+0 / \mathrm{U}_{3}+0 / \mathrm{U}_{4}+0 / \mathrm{U}_{5}+0 / \mathrm{U}_{6}+0 / \mathrm{U}_{7}+0 / \mathrm{U}_{8}+0 / \mathrm{U}_{9}+0 / \mathrm{U}_{10.1}+0 / \mathrm{U}_{10.2}+0 / \mathrm{U}_{11.1}+$ $0 / \mathrm{U}_{11.2}+0 / \mathrm{U}_{11.3}+0 / \mathrm{U}_{11.4}+0 / \mathrm{U}_{12.1}+0 / \mathrm{U}_{12.2}+0 / \mathrm{U}_{12.3}+0 / \mathrm{U}_{13}+0 / \mathrm{U}_{14}+0 / \mathrm{U}_{15.1}+0 / \mathrm{U}_{15.2}+0 / \mathrm{U}_{16}$ $+0 / \mathrm{U}_{17.1}+0 / \mathrm{U}_{17.2}+0 / \mathrm{U}_{17.3}+0 / \mathrm{U}_{18.1}+0 / \mathrm{U}_{18.2}+0 / \mathrm{U}_{19.1}+0 / \mathrm{U}_{19.2}+0 / \mathrm{U}_{20}+0 / \mathrm{U}_{21}+\mathbf{0 . 5} / \mathbf{U}_{\mathbf{2 2}}+$ $1 / \mathrm{U}_{23}+0.5 / \mathbf{U}_{24}$.

A34 $=0 / \mathrm{U}_{1}+0 / \mathrm{U}_{2}+0 / \mathrm{U}_{3}+0 / \mathrm{U}_{4}+0 / \mathrm{U}_{5}+0 / \mathrm{U}_{6}+0 / \mathrm{U}_{7}+0 / \mathrm{U}_{8}+0 / \mathrm{U}_{9}+0 / \mathrm{U}_{10.1}+0 / \mathrm{U}_{10.2}+0 / \mathrm{U}_{11.1}+$ $0 / \mathrm{U}_{11.2}+0 / \mathrm{U}_{11.3}+0 / \mathrm{U}_{11.4}+0 / \mathrm{U}_{12.1}+0 / \mathrm{U}_{12.2}+0 / \mathrm{U}_{12.3}+0 / \mathrm{U}_{13}+0 / \mathrm{U}_{14}+0 / \mathrm{U}_{15.1}+0 / \mathrm{U}_{15.2}+0 / \mathrm{U}_{16}$ $+0 / \mathrm{U}_{17.1}+0 / \mathrm{U}_{17.2}+0 / \mathrm{U}_{17.3}+0 / \mathrm{U}_{18.1}+0 / \mathrm{U}_{18.2}+0 / \mathrm{U}_{19.1}+0 / \mathrm{U}_{19.2}+0 / \mathrm{U}_{20}+0 / \mathrm{U}_{21}+\mathbf{1} / \mathbf{U}_{\mathbf{2 2}}+$ $0.5 / U_{23}+1 / U_{24}$.

Hasil Fuzzifikasi dalam bentuk tabel dapat dilihat pada tabel 5 beserta dengan interval yang digunakan sebagai downward dan upward.

Tabel 5. Hasil Fuzzifikasi

\begin{tabular}{|lcc|c|c|c|}
\hline \multicolumn{3}{|c|}{ Fuzzy Set } & Downward 0.25 Point & Middle Value & Upward 0.75 Point \\
\hline A1 & $=$ & U1 & 646.25 & 647.5 & 648.8 \\
\hline A2 & $=$ & U3 & 656.25 & 657.5 & 658.8 \\
\hline A3 & $=$ & U4 & 661.25 & 662.5 & 663.8 \\
\hline
\end{tabular}


Rizka Zulfikar; Prihatini, Pengujian Metode Fuzzy....

\begin{tabular}{|c|c|c|c|c|c|}
\hline A4 & $=$ & U5 & 666.25 & 667.5 & 668.8 \\
\hline A5 & $=$ & U6 & 671.25 & 672.5 & 673.8 \\
\hline A6 & $=$ & U7 & 676.3 & 677.5 & 678.8 \\
\hline A7 & $=$ & U8 & 681.3 & 682.5 & 683.8 \\
\hline A8 & $=$ & U9 & 686.3 & 687.5 & 688.8 \\
\hline A9 & $=$ & U10.1 & 690.6 & 691.3 & 691.9 \\
\hline A10 & $=$ & U10.2 & 693.1 & 693.8 & 694.4 \\
\hline A11 & $=$ & U11.1 & 695.3 & 695.6 & 695.9 \\
\hline A12 & $=$ & U11.2 & 696.6 & 696.9 & 697.2 \\
\hline A13 & $=$ & U11.3 & 697.8 & 698.1 & 698.4 \\
\hline A14 & $=$ & U11.4 & 699.1 & 699.4 & 699.7 \\
\hline A15 & $=$ & U12.1 & 700.4 & 700.8 & 701.3 \\
\hline A16 & $=$ & U12.2 & 702.1 & 702.5 & 702.9 \\
\hline A17 & $=$ & U12.3 & 703.8 & 704.2 & 704.6 \\
\hline A18 & $=$ & U13 & 706.3 & 707.5 & 708.8 \\
\hline A19 & $=$ & U14 & 711.3 & 712.5 & 713.8 \\
\hline A20 & $=$ & U15.1 & 715.6 & 716.3 & 716.9 \\
\hline A21 & $=$ & U15.2 & 718.1 & 718.8 & 719.4 \\
\hline A22 & $=$ & U16 & 721.3 & 722.5 & 723.8 \\
\hline A23 & $=$ & U17.1 & 725.4 & 725.8 & 726.3 \\
\hline A24 & $=$ & U17.2 & 727.1 & 727.5 & 727.9 \\
\hline A25 & $=$ & U17.3 & 728.8 & 729.2 & 729.6 \\
\hline A26 & $=$ & U18.1 & 730.6 & 731.3 & 731.9 \\
\hline A27 & $=$ & U18.2 & 733.1 & 733.8 & 734.4 \\
\hline A28 & $=$ & U19.1 & 735.6 & 736.3 & 736.9 \\
\hline A29 & $=$ & U19.2 & 738.1 & 738.8 & 739.4 \\
\hline A30 & $=$ & U20 & 741.3 & 742.5 & 743.8 \\
\hline A31 & $=$ & U21 & 746.3 & 747.5 & 748.8 \\
\hline A32 & $=$ & U22 & 751.3 & 752.5 & 753.8 \\
\hline A33 & $=$ & U23 & 756.3 & 757.5 & 758.8 \\
\hline A34 & $=$ & U24 & 761.3 & 762.5 & 763.8 \\
\hline
\end{tabular}

- Hasil pendistribusian Fuzzy set ke dalam data aktual dapat dilihat pada tabel 6 berikut ini :

Tabel 6. Distribusi Fuzzy Set ke dalam Data Aktual

\begin{tabular}{|c|r|c|r|r|c|}
\hline No & Indeks & $\begin{array}{c}\text { Fuzzy } \\
\text { Set }\end{array}$ & No & Indeks & $\begin{array}{c}\text { Fuzzy } \\
\text { Set }\end{array}$ \\
\hline 1 & 689.93 & A 8 & 76 & 700.22 & A15 \\
\hline 2 & 674.4 & A5 & 77 & 698.32 & A13 \\
\hline 3 & 677.97 & A6 & 78 & 717.57 & A21 \\
\hline 4 & 680.87 & A 7 & 79 & 718.88 & A21 \\
\hline 5 & 685.62 & A 8 & 80 & 717.3 & A20 \\
\hline$\ldots$ & $\ldots \ldots \ldots \ldots$ & $\ldots \ldots \ldots .$. & $\ldots \ldots$ & $\ldots \ldots \ldots .$. & $\ldots \ldots \ldots .$. \\
\hline$\ldots$ & $\ldots \ldots \ldots \ldots$ & $\ldots \ldots \ldots .$. & $\ldots \ldots$ & $\ldots \ldots \ldots .$. & $\ldots \ldots \ldots \ldots$ \\
\hline 70 & 705.44 & A18 & 145 & 749.02 & A31 \\
\hline 71 & 704.36 & A17 & 146 & 740.79 & A30 \\
\hline 72 & 698.66 & A12 & 147 & 743.32 & A30 \\
\hline 73 & 699.25 & A14 & 148 & 747.72 & A31 \\
\hline 74 & 695.00 & A10 & 149 & 748.01 & A31 \\
\hline 75 & 697.27 & A12 & 150 & 750.05 & A32 \\
\hline
\end{tabular}

- Berdasarkan hasil distribusi fuzzy set, maka FLR yang terbentuk adalah sebagai berikut :

Tabel 7. Fuzzy Logical Relationships (FLR) 
Rizka Zulfikar; Prihatini, Pengujian Metode Fuzzy....

\begin{tabular}{|c|c|c|c|c|}
\hline $\mathrm{A} 8 \rightarrow \mathrm{A} 5$ & $\mathrm{~A} 15 \rightarrow \mathrm{A} 15$ & $\mathrm{~A} 12 \rightarrow \mathrm{A} 13$ & $\mathrm{~A} 27-\mathrm{A} 25$ & A29-A27 \\
\hline $\mathrm{A} 5 \rightarrow \mathrm{A} 6$ & $\mathrm{~A} 15 \rightarrow \mathrm{A} 12$ & $\mathrm{~A} 13 \rightarrow \mathrm{A} 13$ & $\mathrm{~A} 25-\mathrm{A} 22$ & A27-A28 \\
\hline $\mathrm{A} 6 \rightarrow \mathrm{A} 7$ & $\mathrm{~A} 12 \rightarrow \mathrm{A} 9$ & $\mathrm{~A} 13 \rightarrow \mathrm{A} 14$ & A22-A22 & A28-A27 \\
\hline $\mathrm{A} 7 \rightarrow \mathrm{A} 8$ & $\mathrm{~A} 9 \rightarrow \mathrm{A} 9$ & $\mathrm{~A} 14 \rightarrow \mathrm{A} 13$ & A22-A22 & A27-A24 \\
\hline $\mathrm{A} 8 \rightarrow \mathrm{A} 7$ & $\mathrm{~A} 9 \rightarrow \mathrm{A} 8$ & $\mathrm{~A} 13 \rightarrow \mathrm{A} 13$ & A22-A22 & A24-A27 \\
\hline $\mathrm{A} 7 \rightarrow \mathrm{A} 11$ & $\mathrm{~A} 8 \rightarrow \mathrm{A} 8$ & $\mathrm{~A} 13 \rightarrow \mathrm{A} 10$ & A23-A22 & A27-A28 \\
\hline $\mathrm{A} 11 \rightarrow \mathrm{A} 17$ & $\mathrm{~A} 8 \rightarrow \mathrm{A} 11$ & $\mathrm{~A} 10 \rightarrow \mathrm{A} 13$ & A22-A19 & A28-A29 \\
\hline $\mathrm{A} 17 \rightarrow \mathrm{A} 18$ & $\mathrm{~A} 11 \rightarrow \mathrm{A} 12$ & $\mathrm{~A} 13 \rightarrow \mathrm{A} 12$ & A19-A20 & A29-A27 \\
\hline $\mathrm{A} 18 \rightarrow \mathrm{A} 18$ & $\mathrm{~A} 12 \rightarrow \mathrm{A} 8$ & $\mathrm{~A} 12 \rightarrow \mathrm{A} 18$ & A20-A21 & A27-A28 \\
\hline $\mathrm{A} 18 \rightarrow \mathrm{A} 15$ & $\mathrm{~A} 8 \rightarrow \mathrm{A} 8$ & $\mathrm{~A} 18 \rightarrow \mathrm{A} 17$ & A21-A29 & A28-A26 \\
\hline $\mathrm{A} 15 \rightarrow \mathrm{A} 18$ & $\mathrm{~A} 8 \rightarrow \mathrm{A} 10$ & $\mathrm{~A} 17 \rightarrow \mathrm{A} 12$ & A29-A30 & A26-A24 \\
\hline $\mathrm{A} 18 \rightarrow \mathrm{A} 18$ & $\mathrm{~A} 10 \rightarrow \mathrm{A} 11$ & $\mathrm{~A} 12 \rightarrow \mathrm{A} 14$ & A30-A30 & A24-A25 \\
\hline $\mathrm{A} 18 \rightarrow \mathrm{A} 18$ & $\mathrm{~A} 11 \rightarrow \mathrm{A} 14$ & $\mathrm{~A} 14 \rightarrow \mathrm{A} 10$ & A $30-\mathrm{A} 30$ & A $25-\mathrm{A} 27$ \\
\hline $\mathrm{A} 18 \rightarrow \mathrm{A} 12$ & $\mathrm{~A} 14 \rightarrow \mathrm{A} 12$ & $\mathrm{~A} 10 \rightarrow \mathrm{A} 12$ & A30-A29 & A27-A31 \\
\hline $\mathrm{A} 12 \rightarrow \mathrm{A} 10$ & $\mathrm{~A} 12 \rightarrow \mathrm{A} 9$ & $\mathrm{~A} 12 \rightarrow \mathrm{A} 15$ & A29-A28 & A $31-A 30$ \\
\hline $\mathrm{A} 10 \rightarrow \mathrm{A} 8$ & $\mathrm{~A} 9 \rightarrow \mathrm{A} 8$ & $\mathrm{~A} 15 \rightarrow \mathrm{A} 13$ & A28-A24 & A $30-A 27$ \\
\hline $\mathrm{A} 8 \rightarrow \mathrm{A} 6$ & $\mathrm{~A} 8 \rightarrow \mathrm{A} 12$ & $\mathrm{~A} 13 \rightarrow \mathrm{A} 21$ & A24-A24 & A27-A27 \\
\hline $\mathrm{A} 6 \rightarrow \mathrm{A} 5$ & $\mathrm{~A} 12 \rightarrow \mathrm{A} 15$ & $\mathrm{~A} 21 \rightarrow \mathrm{A} 21$ & A24-A24 & A27-A 30 \\
\hline $\mathrm{A} 5 \rightarrow \mathrm{A} 4$ & $\mathrm{~A} 15 \rightarrow \mathrm{A} 16$ & $\mathrm{~A} 21 \rightarrow \mathrm{A} 20$ & A24-A26 & $\mathrm{A} 30-\mathrm{A} 31$ \\
\hline $\mathrm{A} 4 \rightarrow \mathrm{A} 2$ & $\mathrm{~A} 16 \rightarrow \mathrm{A} 18$ & $\mathrm{~A} 20 \rightarrow \mathrm{A} 21$ & A26-A24 & A31-A31 \\
\hline $\mathrm{A} 2 \rightarrow \mathrm{A} 1$ & $\mathrm{~A} 18 \rightarrow \mathrm{A} 15$ & $\mathrm{~A} 21 \rightarrow \mathrm{A} 19$ & A24-A22 & A31-A34 \\
\hline $\mathrm{A} 1 \rightarrow \mathrm{A} 3$ & $\mathrm{~A} 15 \rightarrow \mathrm{A} 14$ & $\mathrm{~A} 19 \rightarrow \mathrm{A} 20$ & A22-A23 & A34-A32 \\
\hline $\mathrm{A} 3 \rightarrow \mathrm{A} 7$ & $\mathrm{~A} 14 \rightarrow \mathrm{A} 13$ & $\mathrm{~A} 20 \rightarrow \mathrm{A} 20$ & A23-A25 & A32-A32 \\
\hline $\mathrm{A} 7 \rightarrow \mathrm{A} 11$ & $\mathrm{~A} 13 \rightarrow \mathrm{A} 15$ & $\mathrm{~A} 20 \rightarrow \mathrm{A} 19$ & A25-A23 & A32-A33 \\
\hline $\mathrm{A} 11 \rightarrow \mathrm{A} 10$ & $\mathrm{~A} 15 \rightarrow \mathrm{A} 18$ & $\mathrm{~A} 19 \rightarrow \mathrm{A} 22$ & A23-A21 & A33-A31 \\
\hline $\mathrm{A} 10 \rightarrow \mathrm{A} 9$ & $\mathrm{~A} 18 \rightarrow \mathrm{A} 13$ & $\mathrm{~A} 22 \rightarrow \mathrm{A} 22$ & A21-A22 & A31-A30 \\
\hline $\mathrm{A} 9 \rightarrow \mathrm{A} 12$ & $\mathrm{~A} 13 \rightarrow \mathrm{A} 15$ & $\mathrm{~A} 22 \rightarrow \mathrm{A} 21$ & A22-A30 & A30-A30 \\
\hline $\mathrm{A} 12 \rightarrow \mathrm{A} 15$ & $\mathrm{~A} 15 \rightarrow \mathrm{A} 11$ & $\mathrm{~A} 21 \rightarrow \mathrm{A} 23$ & A30-A29 & A30-A31 \\
\hline $\mathrm{A} 15 \rightarrow \mathrm{A} 17$ & $\mathrm{~A} 11 \rightarrow \mathrm{A} 10$ & $\mathrm{~A} 23 \rightarrow \mathrm{A} 28$ & A29-A29 & A31-A31 \\
\hline $\mathrm{A} 17 \rightarrow \mathrm{A} 15$ & $\mathrm{~A} 10 \rightarrow \mathrm{A} 12$ & $\mathrm{~A} 28 \rightarrow \mathrm{A} 27$ & A29-A27 & A31-A32 \\
\hline
\end{tabular}

- Hasil perhitungan Difference data aktual untuk (DIFF x 2 + Data n-1) dan (DIFF / 2 + Data n-1) disajikan pada tabel 8 berikut ini.

Tabel 8. DIFFERENCE Data Aktual

\begin{tabular}{|c|l|r|r|r|}
\hline No & Indeks & \multicolumn{1}{|c|}{ DIFF } & \multicolumn{1}{c|}{$\begin{array}{c}\text { (DIFF x 2 + } \\
\text { Data n-1) }\end{array}$} & $\begin{array}{c}\text { (DIFF / 2 + } \\
\text { Data n-1) }\end{array}$ \\
\hline 1 & 689.93 & 0 & 0 & 0 \\
\hline 2 & 674.4 & 0 & 689.93 & 689.93 \\
\hline 3 & 677.97 & -15.53 & 666.635 & 643.34 \\
\hline 4 & 680.87 & 19.1 & 687.52 & 716.17 \\
\hline 5 & 685.62 & -0.67 & 680.535 & 679.53 \\
\hline No & Indeks & DIFF & $\begin{array}{c}\text { (DIFF x 2 + } \\
\text { Data n-1) }\end{array}$ & $\begin{array}{c}\text { (DIFF / 2 + } \\
\text { Data n-1) }\end{array}$ \\
\hline 6 & 682.71 & 1.85 & 686.545 & 689.32 \\
\hline 7 & 695.97 & -7.66 & 678.88 & 667.39 \\
\hline 8 & 703.4 & 16.17 & 704.055 & 728.31 \\
\hline
\end{tabular}


Rizka Zulfikar; Prihatini, Pengujian Metode Fuzzy....

\begin{tabular}{|r|l|r|r|r|}
\hline 9 & 708.42 & -5.83 & 700.485 & 691.74 \\
\hline 10 & 705.69 & -2.41 & 707.215 & 703.6 \\
\hline 11 & 700.74 & -7.75 & 701.815 & 690.19 \\
\hline 12 & 706.43 & -2.22 & 699.63 & 696.3 \\
\hline 13 & 707.6 & 10.64 & 711.75 & 727.71 \\
\hline 14 & 705.69 & -4.52 & 705.34 & 698.56 \\
\hline 15 & 697.35 & -3.08 & 704.15 & 699.53 \\
\hline 16 & 694.24 & -6.43 & 694.135 & 684.49 \\
\hline 17 & 685.8 & 5.23 & 696.855 & 704.7 \\
\hline 18 & 679.4 & -5.33 & 683.135 & 675.14 \\
\hline 19 & 670.01 & 2.04 & 680.42 & 683.48 \\
\hline 20 & 666.57 & -2.99 & 668.515 & 664.03 \\
\hline$\ldots$ & $\ldots \ldots \ldots \ldots$ & $\ldots \ldots \ldots \ldots$ & $\ldots \ldots \ldots \ldots$ & $\ldots \ldots \ldots \ldots$ \\
\hline$\ldots$ & $\ldots \ldots \ldots \ldots$ & $\ldots \ldots \ldots .$. & $\ldots \ldots \ldots \ldots$ & $\ldots \ldots \ldots \ldots$ \\
\hline 130 & 731.14 & 7.45 & 739.155 & 750.33 \\
\hline 131 & 727.89 & -6.67 & 727.805 & 717.8 \\
\hline 132 & 729.05 & 1.04 & 728.41 & 729.97 \\
\hline 133 & 734.8 & 4.41 & 731.255 & 737.87 \\
\hline 134 & 748.27 & 4.59 & 737.095 & 743.98 \\
\hline 135 & 744.04 & 7.72 & 752.13 & 763.71 \\
\hline 136 & 733.67 & -17.7 & 735.19 & 708.64 \\
\hline 137 & 734.02 & -6.14 & 730.6 & 721.39 \\
\hline 138 & 744.63 & 10.72 & 739.38 & 755.46 \\
\hline 139 & 748.59 & 10.26 & 749.76 & 765.15 \\
\hline 140 & 749.6 & -6.65 & 745.265 & 735.29 \\
\hline 141 & 764.64 & -2.95 & 748.125 & 743.7 \\
\hline 142 & 754.87 & 14.03 & 771.655 & 792.7 \\
\hline 143 & 751.06 & -24.81 & 742.465 & 705.25 \\
\hline 144 & 755.24 & 5.96 & 754.04 & 762.98 \\
\hline 145 & 749.02 & 7.99 & 759.235 & 771.22 \\
\hline 146 & 740.79 & -10.4 & 743.82 & 728.22 \\
\hline 147 & 743.32 & -2.01 & 739.785 & 736.77 \\
\hline 148 & 747.72 & 10.76 & 748.7 & 764.84 \\
\hline 149 & 748.01 & 1.87 & 748.655 & 751.46 \\
\hline 150 & 750.05 & -4.11 & 745.955 & 739.79 \\
\hline
\end{tabular}

- Hasil pengujian metode fuzzied time series Chen dan Hsu (2004) terhadap data indeks bursa saham JII periode Nopember 2017 sampai dengan 14 Juli 2017 adalah sebagai berikut :

Tabel 9. Hasil Pengujian Metode Chen dan Hsu (2004) Untuk Periode Tanggal 23 Nopember 2016 - 14 Juli 2017

\begin{tabular}{|c|r|r|l|r|r|r|}
\hline No & Tanggal & \multicolumn{1}{|c|}{ Aktual } & Trend Peramalan & \multicolumn{1}{c|}{ Prediksi. } & \multicolumn{1}{c|}{ Var } & \multicolumn{1}{c|}{ AFER } \\
\hline 1 & 23-Nov-16 & 689.93 & Middle Value & 672.50 & 1.90 & $0.28 \%$ \\
\hline 2 & 24-Nov-16 & 674.4 & Downward 0.25 & 676.25 & 1.72 & $0.25 \%$ \\
\hline 3 & 25-Nov-16 & 677.97 & Middle Value & 682.50 & -1.63 & $-0.24 \%$ \\
\hline 4 & 28-Nov-16 & 680.87 & Middle Value & 687.50 & -1.88 & $-0.27 \%$ \\
\hline No & Tanggal & Aktual & Trend Peramalan & Prediksi. & \multicolumn{1}{|c|}{ Var } & AFER \\
\hline 5 & 29-Nov-16 & 685.62 & Middle Value & 682.50 & 0.21 & $0.03 \%$ \\
\hline 6 & 30-Nov-16 & 682.71 & Middle Value & 695.63 & 0.35 & $0.05 \%$ \\
\hline 7 & 1-Dec-16 & 695.97 & Downward 0.25 & 703.75 & -0.35 & $-0.05 \%$ \\
\hline 8 & 2-Dec-16 & 703.40 & Middle Value & 707.50 & 0.92 & $0.13 \%$ \\
\hline 9 & 5-Dec-16 & 708.42 & Downward 0.25 & 706.25 & -0.56 & $-0.08 \%$ \\
\hline 10 & 6-Dec-16 & 705.69 & Middle Value & 700.83 & -0.09 & $-0.01 \%$ \\
\hline 11 & 7-Dec-16 & 700.74 & Middle Value & 707.50 & -1.07 & $-0.15 \%$ \\
\hline
\end{tabular}


Rizka Zulfikar; Prihatini, Pengujian Metode Fuzzy....

\begin{tabular}{|c|c|c|c|c|c|c|}
\hline 12 & 8-Dec-16 & 706.43 & Middle Value & 706.25 & 1.35 & $0.19 \%$ \\
\hline 13 & 9-Dec-16 & 707.60 & Downward 0.25 & 706.25 & -0.56 & $-0.08 \%$ \\
\hline 14 & 13-Dec-16 & 705.69 & Middle Value & 696.88 & 0.48 & $0.07 \%$ \\
\hline 15 & 14-Dec-16 & 697.35 & Downward 0.25 & 693.13 & 1.12 & $0.16 \%$ \\
\hline 16 & 15-Dec-16 & 694.24 & Middle Value & 687.50 & -1.70 & $-0.25 \%$ \\
\hline 17 & 16-Dec-16 & 685.8 & Upward 0.75 & 676.25 & 3.15 & $0.46 \%$ \\
\hline 18 & 19-Dec-16 & 679.4 & Middle Value & 672.50 & -2.49 & $-0.37 \%$ \\
\hline 19 & 20-Dec-16 & 670.01 & Downward 0.25 & 666.25 & 0.32 & $0.05 \%$ \\
\hline 20 & 21-Dec-16 & 666.57 & Middle Value & 657.50 & -1.80 & $-0.27 \%$ \\
\hline 21 & 22-Dec-16 & 655.7 & Middle Value & 647.50 & 0.60 & $0.09 \%$ \\
\hline 22 & 23-Dec-16 & 648.1 & Middle Value & 662.50 & -1.54 & $-0.23 \%$ \\
\hline 23 & 27-Dec-16 & 660.96 & Middle Value & 682.50 & -2.28 & $-0.34 \%$ \\
\hline 24 & 28-Dec-16 & 680.22 & Middle Value & 695.63 & 0.50 & $0.07 \%$ \\
\hline 25 & 29-Dec-16 & 696.13 & Downward 0.25 & 693.13 & 1.01 & $0.14 \%$ \\
\hline 26 & 30-Dec-16 & 694.13 & Middle Value & 691.25 & 0.27 & $0.04 \%$ \\
\hline 27 & 3-Jan-17 & 691.52 & Middle Value & 696.88 & -0.51 & $-0.07 \%$ \\
\hline 28 & 4-Jan-17 & 696.36 & Downward 0.25 & 700.42 & 0.02 & $0.00 \%$ \\
\hline 29 & 5-Jan-17 & 700.44 & Middle Value & 704.17 & -0.30 & $-0.04 \%$ \\
\hline 30 & 6-Jan-17 & 703.87 & Middle Value & 704.17 & -3.56 & $-0.51 \%$ \\
\hline 31 & 9-Jan-17 & 700.61 & Middle Value & 704.17 & -3.06 & $-0.44 \%$ \\
\hline 32 & 10-Jan-17 & 701.11 & Middle Value & 696.88 & -0.50 & $-0.07 \%$ \\
\hline 33 & 11-Jan-17 & 696.37 & Middle Value & 691.25 & 1.24 & $0.18 \%$ \\
\hline 34 & 12-Jan-17 & 692.49 & Middle Value & 691.25 & 0.01 & $0.00 \%$ \\
\hline 35 & 13-Jan-17 & 691.26 & Middle Value & 687.50 & 0.68 & $0.10 \%$ \\
\hline 36 & 16-Jan-17 & 688.18 & Downward 0.25 & 686.25 & 2.65 & $0.38 \%$ \\
\hline 37 & 17-Jan-17 & 688.9 & Middle Value & 695.63 & 0.50 & $0.07 \%$ \\
\hline 38 & 18-Jan-17 & 696.12 & Middle Value & 696.88 & 0.46 & $0.07 \%$ \\
\hline 39 & 19-Jan-17 & 697.33 & Upward 0.75 & 688.75 & -1.51 & $-0.22 \%$ \\
\hline 40 & 20-Jan-17 & 687.24 & Middle Value & 687.50 & 0.23 & $0.03 \%$ \\
\hline 41 & 23-Jan-17 & 687.73 & Downward 0.25 & 693.13 & 1.51 & $0.22 \%$ \\
\hline 42 & 24-Jan-17 & 694.63 & Middle Value & 695.63 & 0.26 & $0.04 \%$ \\
\hline 43 & 25-Jan-17 & 695.89 & Middle Value & 699.38 & 0.00 & $0.00 \%$ \\
\hline 44 & 26-Jan-17 & 699.37 & Middle Value & 696.88 & -0.43 & $-0.06 \%$ \\
\hline 45 & 27-Jan-17 & 696.44 & Middle Value & 691.25 & -0.66 & $-0.10 \%$ \\
\hline 46 & 30-Jan-17 & 690.59 & Downward 0.25 & 686.25 & 3.07 & $0.45 \%$ \\
\hline 47 & 31-Jan-17 & 689.32 & Middle Value & 696.88 & -0.60 & $-0.09 \%$ \\
\hline 48 & 1-Feb-17 & 696.28 & Downward 0.25 & 700.42 & 0.68 & $0.10 \%$ \\
\hline 49 & 2-Feb-17 & 701.1 & Middle Value & 702.50 & -0.06 & $-0.01 \%$ \\
\hline 50 & 3-Feb-17 & 702.44 & Middle Value & 707.50 & -2.46 & $-0.35 \%$ \\
\hline 51 & 6-Feb-17 & 705.04 & Middle Value & 704.17 & -3.87 & $-0.55 \%$ \\
\hline 52 & 7-Feb-17 & 700.3 & Middle Value & 699.38 & -0.53 & $-0.08 \%$ \\
\hline 53 & 8-Feb-17 & 698.84 & Middle Value & 698.13 & 0.48 & $0.07 \%$ \\
\hline 54 & 9-Feb-17 & 698.6 & Upward 0.75 & 701.25 & 0.33 & $0.05 \%$ \\
\hline 55 & 10 -Feb-17 & 701.58 & Upward 0.75 & 708.75 & -3.62 & $-0.51 \%$ \\
\hline 56 & 13-Feb-17 & 705.13 & Middle Value & 698.13 & 0.46 & $0.07 \%$ \\
\hline No & Tanggal & Aktual & Trend Peramalan & Prediksi. & Var & AFER \\
\hline 57 & $14-F e b-17$ & 698.58 & Middle Value & 700.83 & 0.74 & $0.11 \%$ \\
\hline 58 & 16-Feb-17 & 701.57 & Middle Value & 695.63 & -0.09 & $-0.01 \%$ \\
\hline 59 & 17-Feb-17 & 695.54 & Middle Value & 693.75 & 0.91 & $0.13 \%$ \\
\hline 60 & 20-Feb-17 & 694.66 & Downward 0.25 & 696.56 & 0.01 & $0.00 \%$ \\
\hline 61 & 21-Feb-17 & 696.57 & Middle Value & 698.13 & -0.57 & $-0.08 \%$ \\
\hline 62 & 22-Feb-17 & 697.56 & Middle Value & 698.13 & -0.12 & $-0.02 \%$ \\
\hline 63 & 23-Feb-17 & 698.01 & Middle Value & 699.38 & 0.50 & $0.07 \%$ \\
\hline 64 & 24-Feb-17 & 699.87 & Middle Value & 698.13 & -0.11 & $-0.02 \%$ \\
\hline 65 & 27-Feb-17 & 698.02 & Middle Value & 698.13 & -0.04 & $-0.01 \%$ \\
\hline 66 & 28-Feb-17 & 698.08 & Middle Value & 693.75 & 0.29 & $0.04 \%$ \\
\hline 67 & 1-Mar-17 & 694.04 & Middle Value & 698.13 & -0.11 & $-0.02 \%$ \\
\hline 68 & 2-Mar-17 & 698.02 & Middle Value & 696.88 & -0.30 & $-0.04 \%$ \\
\hline 69 & 3-Mar-17 & 696.57 & Middle Value & 707.50 & -2.06 & $-0.29 \%$ \\
\hline
\end{tabular}


Rizka Zulfikar; Prihatini, Pengujian Metode Fuzzy....

\begin{tabular}{|c|c|c|c|c|c|c|}
\hline 70 & 6-Mar-17 & 705.44 & Middle Value & 704.17 & 0.19 & $0.03 \%$ \\
\hline 71 & 7-Mar-17 & 704.36 & Middle Value & 696.88 & 1.78 & $0.26 \%$ \\
\hline 72 & 8-Mar-17 & 698.66 & Middle Value & 699.38 & -0.13 & $-0.02 \%$ \\
\hline 73 & 9-Mar-17 & 699.25 & Middle Value & 693.75 & 1.25 & $0.18 \%$ \\
\hline 74 & 10-Mar-17 & 695.00 & Middle Value & 696.88 & 0.39 & $0.06 \%$ \\
\hline 75 & 13-Mar-17 & 697.27 & Downward 0.25 & 700.42 & -0.20 & $-0.03 \%$ \\
\hline 76 & 14-Mar-17 & 700.22 & Middle Value & 698.13 & 0.20 & $0.03 \%$ \\
\hline 77 & 15-Mar-17 & 698.32 & Middle Value & 718.75 & -1.18 & $-0.16 \%$ \\
\hline 78 & 16-Mar-17 & 717.57 & Middle Value & 718.75 & 0.13 & $0.02 \%$ \\
\hline 79 & 17-Mar-17 & 718.88 & Middle Value & 716.25 & 1.05 & $0.15 \%$ \\
\hline 80 & 20-Mar-17 & 717.30 & Middle Value & 718.75 & -1.07 & $-0.15 \%$ \\
\hline 81 & 21-Mar-17 & 717.68 & Middle Value & 712.50 & 2.35 & $0.33 \%$ \\
\hline 82 & 22-Mar-17 & 714.85 & Middle Value & 716.25 & -0.89 & $-0.12 \%$ \\
\hline 83 & 23-Mar-17 & 715.36 & Downward 0.25 & 715.63 & 0.52 & $0.07 \%$ \\
\hline 84 & 24-Mar-17 & 716.14 & Middle Value & 712.50 & 0.08 & $0.01 \%$ \\
\hline 85 & 27-Mar-17 & 712.58 & Middle Value & 722.50 & 1.77 & $0.24 \%$ \\
\hline 86 & 29-Mar-17 & 724.27 & Middle Value & 722.50 & 0.00 & $0.00 \%$ \\
\hline 87 & 30-Mar-17 & 722.5 & Middle Value & 718.75 & -0.40 & $-0.06 \%$ \\
\hline 88 & 31-Mar-17 & 718.35 & Middle Value & 725.83 & 0.76 & $0.10 \%$ \\
\hline 89 & 3-Apr-17 & 726.59 & Middle Value & 736.25 & -1.18 & $-0.16 \%$ \\
\hline 90 & $4-A p r-17$ & 735.07 & Middle Value & 733.75 & 0.99 & $0.13 \%$ \\
\hline 91 & 5-Apr-17 & 734.74 & Middle Value & 729.17 & 0.23 & $0.03 \%$ \\
\hline 92 & 6-Apr-17 & 729.4 & Middle Value & 722.50 & 1.32 & $0.18 \%$ \\
\hline 93 & $7-A p r-17$ & 723.82 & Downward 0.25 & 721.25 & -0.19 & $-0.03 \%$ \\
\hline 94 & 10-Apr-17 & 721.06 & Downward 0.25 & 721.25 & -0.82 & $-0.11 \%$ \\
\hline 95 & 27-Mar-17 & 712.58 & Middle Value & 725.83 & 0.74 & $0.10 \%$ \\
\hline 96 & 29-Mar-17 & 724.27 & Middle Value & 725.83 & 0.74 & $-0.11 \%$ \\
\hline 97 & 30-Mar-17 & 722.5 & Middle Value & 722.50 & -0.80 & $0.19 \%$ \\
\hline 98 & 31-Mar-17 & 718.35 & Middle Value & 712.50 & 1.35 & $0.15 \%$ \\
\hline 99 & $3-A p r-17$ & 726.59 & Middle Value & 716.25 & 1.11 & $-0.05 \%$ \\
\hline 100 & 4-Apr-17 & 735.07 & Middle Value & 718.75 & -0.33 & $0.14 \%$ \\
\hline 101 & 5-Apr-17 & 734.74 & Middle Value & 738.75 & 1.05 & $-0.31 \%$ \\
\hline 102 & 6-Apr-17 & 729.4 & Middle Value & 742.50 & -2.33 & $0.30 \%$ \\
\hline 103 & $7-A p r-17$ & 723.82 & Middle Value & 742.50 & 2.26 & $0.23 \%$ \\
\hline 104 & 10-Apr-17 & 721.06 & Middle Value & 742.50 & 1.71 & $-0.08 \%$ \\
\hline 105 & 11-Apr-17 & 720.43 & Middle Value & 738.75 & -0.56 & $0.08 \%$ \\
\hline 106 & 12-Apr-17 & 726.57 & Downward 0.25 & 735.63 & 0.57 & $0.02 \%$ \\
\hline 107 & 13-Apr-17 & 721.7 & Middle Value & 727.50 & 0.16 & $0.07 \%$ \\
\hline 108 & 17-Apr-17 & 713.85 & Middle Value & 727.50 & 0.48 & $-0.09 \%$ \\
\hline No & Tanggal & Aktual & Trend Peramalan & Prediksi. & Var & AFER \\
\hline 109 & 18-Apr-17 & 717.36 & Middle Value & 727.50 & -0.68 & $0.08 \%$ \\
\hline 110 & 20-Apr-17 & 718.42 & Middle Value & 731.25 & 0.58 & $0.11 \%$ \\
\hline 111 & 21-Apr-17 & 739.8 & Middle Value & 727.50 & 0.83 & $0.24 \%$ \\
\hline 112 & 25-Apr-17 & 740.17 & Downward 0.25 & 721.25 & 1.77 & $0.04 \%$ \\
\hline 113 & 26-Apr-17 & 744.76 & Middle Value & 725.83 & 0.29 & $0.03 \%$ \\
\hline 114 & 27-Apr-17 & 744.21 & Middle Value & 729.17 & 0.19 & $0.11 \%$ \\
\hline 115 & 28-Apr-17 & 738.19 & Middle Value & 725.83 & 0.78 & $0.04 \%$ \\
\hline 116 & 2-May-17 & 736.19 & Middle Value & 718.75 & 0.31 & $-0.32 \%$ \\
\hline 117 & 3-May-17 & 727.66 & Middle Value & 722.50 & -2.34 & $0.01 \%$ \\
\hline 118 & 4-May-17 & 727.98 & Middle Value & 742.50 & 0.06 & $-0.08 \%$ \\
\hline 119 & 5-May-17 & 726.82 & Middle Value & 738.75 & -0.60 & $-0.05 \%$ \\
\hline 120 & 8-May-17 & 731.83 & Middle Value & 738.75 & -0.39 & $-0.07 \%$ \\
\hline 121 & 9-May-17 & 728.33 & Middle Value & 733.75 & -0.50 & $0.17 \%$ \\
\hline 122 & 10-May-17 & 723.02 & Middle Value & 736.25 & 1.25 & $0.16 \%$ \\
\hline 123 & 12-Мay-17 & 726.12 & Middle Value & 733.75 & 1.20 & $0.03 \%$ \\
\hline 124 & 15-May-17 & 729.36 & Middle Value & 727.50 & 0.20 & $-0.01 \%$ \\
\hline 125 & 16-Мay-17 & 726.61 & Middle Value & 733.75 & -0.06 & $0.10 \%$ \\
\hline 126 & 17-Мay-17 & 719.06 & Middle Value & 736.25 & 0.76 & $-0.09 \%$ \\
\hline 127 & 18-May-17 & 720.16 & Middle Value & 738.75 & -0.63 & $-0.18 \%$ \\
\hline
\end{tabular}


Rizka Zulfikar; Prihatini, Pengujian Metode Fuzzy....

\begin{tabular}{|r|r|r|l|r|r|r|}
\hline 128 & 19-May-17 & 742.56 & Upward 0.75 & 734.38 & -1.32 & $-0.11 \%$ \\
\hline 129 & 22-May-17 & 738.15 & Middle Value & 736.25 & -0.82 & $-0.02 \%$ \\
\hline 130 & $23-$ May-17 & 738.36 & Middle Value & 731.25 & -0.11 & $0.11 \%$ \\
\hline 131 & $24-$ May-17 & 733.25 & Downward 0.25 & 727.08 & 0.81 & $0.04 \%$ \\
\hline 132 & $26-$ May-17 & 737.5 & Upward 0.75 & 728.75 & 0.30 & $0.14 \%$ \\
\hline 133 & $29-$ May-17 & 734.95 & Middle Value & 733.75 & 1.05 & $0.10 \%$ \\
\hline 134 & 30-May-17 & 727.7 & Middle Value & 747.50 & 0.77 & $0.21 \%$ \\
\hline 135 & 31-May-17 & 733.69 & Middle Value & 742.50 & 1.54 & $-0.01 \%$ \\
\hline 136 & 2-Jun-17 & 737.01 & Middle Value & 733.75 & -0.08 & $0.04 \%$ \\
\hline 137 & 5-Jun-17 & 738.12 & Middle Value & 733.75 & 0.27 & $-0.39 \%$ \\
\hline 138 & 6-Jun-17 & 733.05 & Middle Value & 747.50 & -2.87 & $0.31 \%$ \\
\hline 139 & 7-Jun-17 & 735.43 & Downward 0.25 & 746.25 & 2.34 & $0.45 \%$ \\
\hline 140 & 8-Jun-17 & 731.14 & Downward 0.25 & 746.25 & 3.35 & $0.28 \%$ \\
\hline 141 & 9-Jun-17 & 727.89 & Middle Value & 762.50 & 2.14 & $0.31 \%$ \\
\hline 142 & 12-Jun-17 & 729.05 & Middle Value & 752.50 & 2.37 & $-0.19 \%$ \\
\hline 143 & 13-Jun-17 & 734.8 & Middle Value & 752.50 & -1.44 & $-0.30 \%$ \\
\hline 144 & 14-Jun-17 & 748.27 & Middle Value & 757.50 & -2.26 & $0.20 \%$ \\
\hline 145 & 15-Jun-17 & 744.04 & Middle Value & 747.50 & 1.52 & $-0.06 \%$ \\
\hline 146 & 16-Jun-17 & 733.67 & Downward 0.25 & 741.25 & -0.46 & $-0.56 \%$ \\
\hline 147 & 19-Jun-17 & 734.02 & Middle Value & 747.50 & -4.18 & $0.20 \%$ \\
\hline 148 & 12-Jul-17 & 747.72 & Downward 0.25 & 746.25 & 1.47 & $0.24 \%$ \\
\hline 149 & 13-Jul-17 & 748.01 & Downward 0.25 & 746.25 & 1.76 & $-0.33 \%$ \\
\hline 150 & 14-Jul-17 & 750.05 & Middle Value & 752.50 & -2.45 & $0.28 \%$ \\
\hline & & & & MSE & $\mathbf{1 . 8 8}$ & \\
\hline & & & & $\mathbf{A F E R}$ & & $\mathbf{0 . 0 0 6 \%}$ \\
\hline & & & & & \\
\hline
\end{tabular}

Dari hasil pengujian data aktual indeks bursa saham JII dengan menggunakan metode Chen dan Hsu, didapatkan nilai MSE sebesar 1.88 dan AFER sebesar $0.006 \%$, sehingga dapat dikatakan bahwa metode Chen dan Hsu memiliki tingkat akurasi yang cukup baik dalam meramalkan trend indeks bursa saham syarih di JII dan cenderung lebih baik dibandingkan metode-metode peramalan lainnya.

Jika nilai aktual dan nilai prediksi disajikan dalam bentuk grafik garis, maka gambaran keakuratan metode Chen dan Hsu dalam melakukan peramalan dapat dilihat pada gambar 1 berikut ini.

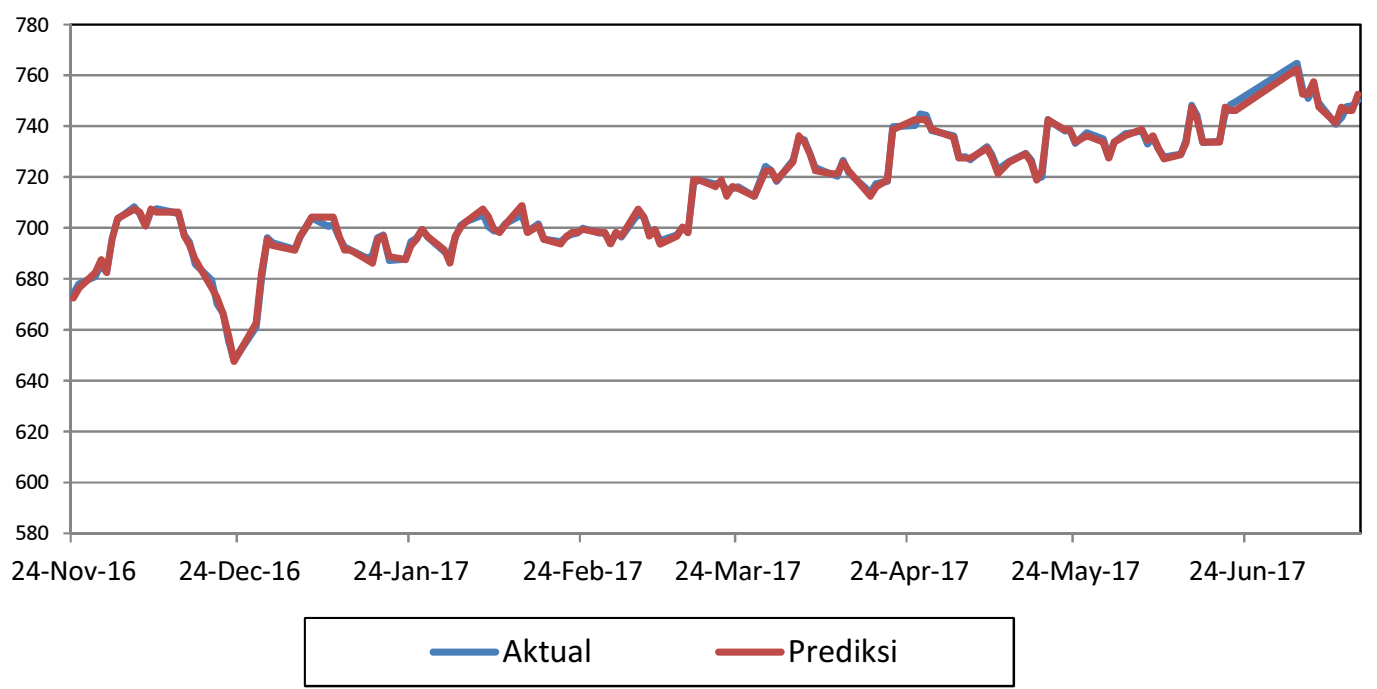


Rizka Zulfikar; Prihatini, Pengujian Metode Fuzzy....

\section{Gambar 1 Grafik Data Aktual dan Data Prediksi Hasil Peramalan Metode Fuzzied Time Series Chen dan Shu (2004)}

Berdasarkan gambar 1 terlihat bahwa grafik garis nilai prediksi dengan metode Chen dan Hsu hampir sebagian besar menutupi grafik garis nilai aktual indeks bursa JII, sehingga hasil peramalan ini dengan metode ini dapat dikatakan sudah mendekati nilai aktual indeks saham JII.
Untuk 3 periode berikutnya yaitu periode tanggal 17,18 dan 19 Juli 2017 , nilai prediksi indeks bursa saham JII menurut Chen dan Hsu adalah sebagai berikut :

Tabel 10. Prediksi Metode Chen dan Hsu untuk 3 Periode Selanjutnya

\begin{tabular}{|r|c|r|}
\hline No & Tanggal & Prediksi \\
\hline 1 & 17-Jul-17 & 753.75 \\
\hline 2 & $18-J u l-17$ & 747.50 \\
\hline 3 & 19-Jul-17 & 741.25 \\
\hline
\end{tabular}

\section{KESIMPULAN DAN SARAN}

Berdasarkan analisis hasil penelitian yang telah diuraikan di atas, dapat disimpulkan bahwa :

1. Metode Chen dan Hsu (2004) dapat digunakan untuk meramalkan trend indeks bursa saham yang terjadi Jakarta Islamic Index dengan tingkat keakuratan yang cukup baik.

2. Metode Chen dan Hsu memiliki nilai MSE $=1.88$ dan AFER $=0.006 \%$ yang jauh lebih baik dibandingkan dengan metode-metode peramalan lainnya.

Berikut merupakan beberapa saran yang dapat dijadikan pertimbangan bagi penelitian selanjutnya :

1. Pada tahap redivided interval pembagian kelas interval dengan jumlah data terbanyak dapat dilakukan dengan pembagian kelas interval yang lebih besar daripada 4 seperti yang disarankan oleh Chen dan Hsu (2004), sehingga diharapkan nilai MSE dan AFER menjadi semakin kecil.

2. Metode Chen dan Hsu (2004) dapat diujikan pada saham-saham yang cukup aktif dan memiliki trend yang sangat berfluktuasi baik bursa saham syariah maupun bursa saham lainnya.

3. Untuk penelitian yang akan datang, metode Chen dan Hsu dapat diujikan dengan jumlah data yang lebih banyak dan periode yang lebih panjang.

\section{DAFTAR PUSTAKA}

Chen, S. M. 1996. Forecasting enrollments based on fuzzy time series. Fuzzy Sets and Systems. 81: 311-319.

Chen, S. M. 2002. Forecasting enrollments based on high-order fuzzy time series. Cybernetics and Systems: An International Journal. 33: 1-16.

Chen, S.M dan Hsu, C.C. 2004. A New Method to Forecast Enrollments Using Fuzzy Time Series. International Journal of Applied Science and Engineering 2 (3) : 234-244.

Cheng, C. H., Cheng, G. W., dan Wang, J. W. 2008. Multi-attribute Fuzzy Time Series Method Based on Fuzzy Clustering. Expert 
systems with applications. 34(2) : 1235-1242

Elfajar, A. B., Setiawan, B. D. Dan Dewi, C. 2017. Peramalan Jumlah Kunjungan Wisatawan Kota Batu Menggunakan Metode Time Invariant Fuzzy Time Series. Jurnal Pengembangan Teknologi Informasi dan Ilmu Komputer. 1 (2) : 85-94.

Fauziah, N., Wahyuningsih, S., dan Nasution, Y.N. 2016. Peramalan Mengunakan Fuzzy Time Series Chen (Studi Kasus: Curah Hujan Kota Samarinda). Statistika. 4(2) : $52-61$.

Hansun, S. 2012. Peramalan Data IHSG Menggunakan Fuzzy Time Series. Indonesian Journal of Computer and Cybernetics System. 6(2): $79-88$.

Rukhansah, N., Muslim, M. A., dan Arifudin, R. 2015. Fuzzy Time Series Markov Chain Dalam Meramalkan Harga Saham. Seminar Nasional Ilmu Komputer (Snik 2015). Semarang, 10 Oktober 2015 : 309-321.

Rahmadiani, A., dan Wiwik, A. 2012. Implementasi Fuzzy Neural Network

Pasien Poli Bedah di Rumah Sakit Onkologi Surabaya. Jurnal Teknik ITS. 1 (1) : 403-407.

Handayani, L., dan Anggriani, D. 2015. Perbandingan Model Chen Dan Model Lee Pada Metode Fuzzy Time Series Untuk Prediksi Harga Emas. Jurnal Pseudocode. 2 (1) : $28-36$.

Hasudungan, F. I., Umbara, R. F dan Triantoro, D. 2016. Prediksi Harga Saham Dengan Metode Fuzzy Time Series dan Metode Fuzzy Time Series-Genetic Algorithm (Studi Kasus: PT Bank Mandiri (persero) Tbk). eProceeding of Engineering : 3 (3) : 5372 - 5377.
Huarng, K. 2001. Heuristic models of fuzzy time series for forecasting. Fuzzy Sets and Systems. 123: 369-386.

Hwang, J. R., Chen, S. M., and Lee, C. H. 1998. Handling forecasting problems using fuzzy time series. Fuzzy Sets and Systems. 100: 217-228.

Jilani, T. A., Burney, S. M. A., dan Ardil, C. 2007. Fuzzy Metric Approach for Fuzzy Time Series Forecasting Based on Frequanecy Density Based Pertioning. Proceedings of world journal academy of scinece, engineering and technology, 23: 333-338.

Rukhansah, N., Muslim, M. A., dan Arifudin, R. 2015. Fuzzy Time Series Markov Chain Dalam Meramalkan Harga Saham. Seminar Nasional Ilmu Komputer (Snik 2015). Semarang, 10 Oktober 2015 : 309-321.

Song, Q. dan Chissom, B. S. 1993. Forecasting enrollments with fuzzy time series - Part I. Fuzzy Sets and Systems. 54: 1-9.

Song, Q. dan Chissom, B. S. 1994. Forecasting enrollments with fuzzy time series - Part II. Fuzzy Sets and Systems. 62: 1-8.

Sullivan, J., dan Woodall, W. H. 1994. A comparison of fuzzy forecasting and

Markov modeling. Fuzzy Sets and Systems. 64: 279-293.

Widoatmodjo, S. 2009. Pasar Modal Indonesia: Pengantar dan Studi Kasus. Ghalia Indonesia. Bogor.

Website :

http://www.idx.co.id diakses pada tanggal 12 Mei 2017

http://www.finance.google.co.id diakses pada tanggal 15 Juli 2017. 